\title{
High Fat Diet Activates Splenic NOD1 and Enhances Neutrophil Recruitment and Neutrophil Extracellular Traps Release in the Spleen of ApoE-Deficient Mice
}

\section{Victoria Fernández-García}

Instituto de Investigaciones Biomédicas Alberto Sols: Instituto de Investigaciones Biomedicas Alberto Sols

\section{Silvia González-Ramos}

Instituto de Investigaciones Biomédicas Alberto Sols: Instituto de Investigaciones Biomedicas Alberto Sols

\section{José Avendaño-Ortiz}

Hospital La Paz: Hospital Universitario La Paz

\section{Paloma Martín-Sanz}

Instituto de Investigaciones Biomédicas Alberto Sols: Instituto de Investigaciones Biomedicas Alberto Sols

\section{Diego Gómez-Coronado}

Hospital Ramon y Cajal: Hospital Universitario Ramon y Cajal

\section{Carmen Delgado}

Alberto Sols Biomedical Research Institute: Instituto de Investigaciones Biomedicas Alberto Sols

Antonio Castrillo

Instituto de Investigaciones Biomédicas Alberto Sols: Instituto de Investigaciones Biomedicas Alberto Sols

\section{Lisardo Bosca ( $\square$ lbosca@iib.uam.es)}

Instituto de Investigaciones Biomedicas Alberto Sols https://orcid.org/0000-0002-0253-5469

\section{Research Article}

Keywords: NOD1, spleen, neutrophils, NETs, high-fat dieT, atherogenesis, partial splenectomy

Posted Date: February 21st, 2022

DOI: https://doi.org/10.21203/rs.3.rs-1351352/v1

License: (c) (1) This work is licensed under a Creative Commons Attribution 4.0 International License.

Read Full License 
High fat diet activates splenic NOD1 and enhances neutrophil recruitment and neutrophil extracellular traps release in the spleen of ApoE-deficient mice

Victoria Fernández-García ${ }^{1,2,, ; a}$, Silvia González-Ramos ${ }^{1, a}$, José Avendaño-Ortiz ${ }^{3}$, Paloma MartínSanz $^{1,4}$, Diego Gómez-Coronado ${ }^{5}$, Carmen Delgado ${ }^{1,2}$, Antonio Castrillo ${ }^{1,6}$, Lisardo Boscá ${ }^{1,2, *}$

${ }^{1}$ Instituto de Investigaciones Biomédicas Alberto Sols (CSIC-UAM), Arturo Duperier 4, 28029 Madrid, Spain

${ }^{2}$ Centro de Investigación Biomédica en Red en Enfermedades Cardiovasculares (CIBERCV), Monforte de Lemos 3-5, 28029 Madrid, Spain

${ }^{3}$ Instituto de Investigación Sanitaria del Hospital Universitario La Paz, IdiPAZ. C. de Pedro Rico, 6, 28029 Madrid, Spain

${ }^{4}$ Centro de Investigación Biomédica en Red de Enfermedades Hepáticas y Digestivas (CIBERehd), Monforte de Lemos 3-5, 28029 Madrid, Spain

${ }^{5}$ Servicio de Bioquímica-Investigación. Hospital Universitario Ramón y Cajal. Ctra. M-607 9,100, 28034 Madrid, and Centro de Investigación Biomédica en Red de Fisiopatología de la Obesidad y Nutrición (CIBERobn), Monforte de Lemos 3-5, 28029 Madrid Spain

${ }^{6}$ Unidad de Biomedicina (Unidad Asociada al CSIC), Instituto Universitario de Investigaciones Biomédicas y Sanitarias (IUIBS) de la Universidad de Las Palmas de Gran Canaria, Las Palmas, Spain

${ }^{a}$ These authors contributed equally to the work

\section{*Address for correspondence:}

Lisardo Boscá or Victoria Fernández-García

Instituto de Investigaciones Biomédicas Alberto Sols (CSIC-UAM)

Arturo Duperier, 4

28029 Madrid

Phone (+34) 914972747

Email: 1bosca@iib.uam.es or bvfernandez@iib.uam.es

Keywords: NOD1; spleen; neutrophils; NETs, high-fat diet; atherogenesis; partial splenectomy 


\begin{abstract}
In the course of atherogenesis, the spleen plays an important role in the regulation of extramedullary hematopoiesis and in the control of circulating immune cells, which contributes to plaque progression. Here, we have investigated the role of splenic nucleotide-binding oligomerization domain 1 (NOD1) in the recruitment of circulating immune cells as well as the involvement of this immune organ in extramedullary hematopoiesis in mice fed a high-fat high-cholesterol diet (HFD). Under HFD conditions, the absence of NOD1 enhances the mobilization of immune cells, mainly neutrophils, from the bone marrow to the blood. To determine the effect of NOD1-dependent mobilization of immune cells under pro-atherogenic

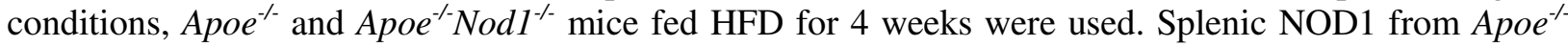
mice was activated after feeding HFD as inferred by the phosphorylation of the NOD1 downstream targets RIPK2 and TAK1. Moreover, this activation was accompanied by the release of neutrophil extracellular traps (NETs), as determined by the increase in the expression of peptidyl arginine deiminase 4, and the identification of citrullinated histone $\mathrm{H} 3$ in this organ. This formation of NETs was significantly reduced in $A p o e^{-/-} \mathrm{Nodl}^{-/-}$mice. Indeed, the presence of $\mathrm{Ly} 6 \mathrm{G}^{+}$cells and the lipidic content in the spleen of mice deficient in Apoe and Nodl was reduced when compared to the Apoe $e^{-/}$counterparts, which suggests that the mobilization and activation of circulating immune cells is altered in the absence of NOD1. Furthermore, confirming previous studies, Apoe ${ }^{-/} \mathrm{Nod}^{-/}$mice showed a reduced atherogenic disease and a diminished recruitment of neutrophils in the spleen, compared to $A p o e^{-/-}$mice. However, splenic artery-ligation reduced the atherogenic burden in Apoe $e^{--}$mice an effect that, unexpectedly was lost in Apoe ${ }^{--} \mathrm{Nod}^{-/}$mice. Together, these results suggest that neutrophil accumulation and activity in the spleen is driven in part by NOD1 activation in mice fed HFD, contributing in this way to regulate atherogenic progression.
\end{abstract}

\title{
Introduction
}

The classical physiological roles of the spleen involve, among others, blood filtration and the regulation, selection and storage of different immune cell populations. Nevertheless, the most important task of this organ under pathological conditions is its hematopoietic activation (1-5). This is because the spleen harbors numerous highly differentiated anatomical structures and cells that allow specific functions due to its direct connection to systemic circulation and further links with the nervous and immune systems (6). Anatomically, the spleen architecture includes heterogeneous populations of stromal, immune and endothelial cells, organized in domains with specific microcirculation (7-11). In addition, some particular immune functions have been ascribed to this versatile organ, such as removal of non-opsonized bacteria, blood cells clearance and sensing the presence of circulating pathogen-associated molecular patterns (PAMPS). In this regard, splenic nucleotide-binding oligomerization domain 1 (NOD1) and NOD2, synergizing with TLR4 activation, have been involved in the mobilization of hematopoietic stem cells from the bone marrow to the spleen, contributing to the host defense against several pathogens $(4,7,12-14)$. Moreover, leukocyte lineages derived from hematopoietic cells, mainly neutrophils releasing neutrophil extracellular traps (NETs) and macrophages, cells that in turn express NOD molecules, exert key roles in the mobilization of hematopoietic cells under pro-inflammatory conditions. In addition to these immune functions, the spleen participates in the modulation of lipid metabolism and plasma lipids content, mechanisms relevant in the onset of atherosclerotic complications and cardiovascular diseases $(10,15-18)$. In fact, elevated plasma LDL-cholesterol levels have been observed both in humans and animal models after splenectomy, suggesting a preeminent role for the spleen in LDL catabolism (19-21). Despite these roles of the spleen in essential immune and metabolic processes, controversies exist regarding the consequences of splenic loss of function. This can occur after a partial or total spleen intervention (i.e.; after ligation of splenic arteries in animal models, traumatic splenectomy or surgical removal in some splenic pathologies) $(8,20-26)$. In contrast, the gain of splenic function has been evidenced in splenomegaly patients $(15,22,27,28)$.

Our data show that NOD1 deletion in mice fed chow diet did not alter the hematopoietic flow from the bone marrow to the blood and the spleen. However, Nod1 ${ }^{-/}$mice fed a high fat diet (HFD) exhibit a significant mobilization of immune cells from the bone marrow into the circulation, accumulating in the spleen. Furthermore, under proatherogenic conditions due to HFD in Apoe $e^{-/}$mice, deletion of NOD1 has a 
significant impact on the accumulation of splenic myeloid cell subpopulations, an effect that is associated to changes in the circulating levels of chemoattractant factors. This increase in circulating immune cells in Apoe ${ }^{-/} \mathrm{Nodl}^{-/}$mice, but its restricted infiltration in tissues with inflammatory tendency (due to Nodl deficiency), contributes to reducing the atherogenic lesion. Interestingly, splenic-artery ligation in Apoe $e^{-/}$ mice fed HFD reduces atherosclerotic disease progression, an effect that is lost in Apoe ${ }^{-/}$Nod1 $^{-/}$mice. Finally, NOD1 activation under HFD conditions contributes to NETs formation in the spleen, playing a role in splenic cells homeostasis.

\section{Materials and methods}

Animal procedures. C57BL/6 (WT) and $A p o e^{-/-}$mice were obtained from Charles River (JAX mice stock \#000664 and \#002052, respectively. Barcelona, Spain). Double-knockout Apoe ${ }^{-/} N o d 1^{-/}$mice were generated by crossing Apoe $e^{--}$mice with $\mathrm{Nodl}^{-/-}$mice as previously described $(29,30)$. Only male mice were used for the experiments. For the spleen surgeries, 8-weeks old mice were randomly assigned to either splenic artery-ligation or the control group (sham). Mice were intubated and anesthetized with $2 \%$ isoflurane. The fur over the left side of the abdomen was carefully shaved, mice were accommodated on a heating pad $\left(37^{\circ} \mathrm{C}\right)$ to avoid temperature loss during operation and skin was disinfected with betadine and alcohol prior to the intervention. The spleen was identified and it was ligated with a 7-0 nylon suture around the splenic arteries to mimic a partial splenic loss of function (splenic hilar ligation group). The small incision in the abdomen and the skin was closed employing absorbable 5-0 sutures and special glue specific for animal tissue (3M $\mathrm{M}^{\mathrm{TM}}$ Vetbond ${ }^{\mathrm{TM}}$ Tissue Adhesive, Saint Paul, MN, USA). Ibuprofen (Dalsy, Mylan, Dublin, Ireland) as analgesic was supplied in drinking water (3 $\mathrm{ml}$ of Dalsy per $250 \mathrm{ml}$ of water) continued for three days after the procedure. The wound healing was monitored daily and adequate recovery after the surgical process was ensured. Three days after sham operation or ligation of splenic-arteries, mice were kept on chow or high-fat diet (HFD, 10.2\% hydrogenated coconut oil, $0.75 \%$ cholesterol; Ssniff, Soest, Germany) for 4 weeks. Nod $1^{-/}$mice fed HFD for 4 weeks did not develop atherogenic lesions. After this feeding period, mice were anaesthetized intraperitoneally under general anesthesia (ketamine/xylazine combination at $80 \mathrm{mg} / \mathrm{kg}$ and $10 \mathrm{mg} / \mathrm{kg}$ body weight, respectively) before euthanasia by $\mathrm{CO}_{2}$ inhalation. Whole blood was extracted postmortem by cardiac puncture and plasma was obtained by centrifugation at $2,000 \mathrm{~g}$ for $10 \mathrm{~min}$ at $4^{\circ} \mathrm{C}$.

Flow cytometry assays. Mice blood, bone marrow (BM) and spleen samples were used for the flow cytometry assays after kept the different mice groups under chow or HFD for 4 weeks, as previously described $(29,30)$. Briefly, to analyze myeloid cell populations in these tissues, cell suspensions were obtained after centrifugation and lysis (blood) or flushing (BM and spleen) and they were prepared by passing the resulting solutions through a $70 \mathrm{~mm}$ cell strainer. After $400 \mathrm{~g}$ centrifugation for $5 \mathrm{~min}$ at $4^{\circ} \mathrm{C}$, the pellet was resuspended in HBSS (Thermo Fisher) supplemented with $10 \mathrm{mM}$ HEPES and $0.5 \%$ bovine serum albumin ( $\mathrm{pH} 7.4$ ) and incubated for 30 min at $4{ }^{\circ} \mathrm{C}$ with: rat APC-Cy7-conjugated $\mathrm{mAb}$ against CD45 (1:200; BioLegend, San Diego, CA, USA), rat PE-conjugated mAb against CD115 (1:100; Thermo Fisher), rat PerCpCy5.5- conjugated mAb against Ly6G (1:100; BioLegend), rat FITC-conjugated mAb against Ly6C (1:100; BioLegend), rat APC-conjugated mAb against F4/80 (1:100; BioLegend), rat PECy7conjugated mAb against $\mathrm{Cd} 11 \mathrm{~b}$ (1:100; eBioscience), rat PECy7-conjugated mAb against Ly6C (1:100; eBioscience), rat FITC-conjugated mAb against CD4 (1:100; BioLegend), rat APC-conjugated mAb against CD8 (1:100; BioLegend), rat PerCp-conjugated mAb against B220 (1:100; BioLegend). For cell counting, DAPI and absolute counting beads were used (Count-Bright; Thermo Fisher). Flow cytometry was conducted in a FACSCanto II (Becton Dickinson), and leukocyte subsets were defined using FlowJo software (Treestar, Ashland, OR, USA): leukocytes $\left(\mathrm{CD} 45^{+}\right)$, neutrophils $\left(\mathrm{CD}^{4} 5^{+} \mathrm{CD}_{11 b^{+}} \mathrm{Ly}_{6 \mathrm{G}}^{+}\right)$, inflammatory monocytes $\left(\mathrm{CD} 45^{+} \mathrm{CD} 115^{+} \mathrm{CD} 11 \mathrm{~b}^{+} \mathrm{Ly}^{+} \mathrm{C}^{+}\right.$), tissue macrophages $\left(\mathrm{CD} 45^{+} \mathrm{F} 4 / 80^{+}\right)$, CD4 lymphocytes $\left(\mathrm{CD} 45^{+} \mathrm{CD} 4^{+}\right), \mathrm{CD} 8$ lymphocytes $\left(\mathrm{CD} 45^{+} \mathrm{CD} 8^{+}\right)$and $\mathrm{B}$ lymphocytes $\left(\mathrm{CD} 45^{+} \mathrm{B} 220^{+}\right)$.

Plasma chemoattractants measurement. 8 weeks-old mice were fed for 4 weeks with HFD and inflammatory mediators and chemoattractants (CCL2, CCL5, CXCL1, CXCL2) were quantified in plasma using the Milliplex Map Mouse Cytokine/Chemokine Magnetic Bead Panel (Merck Millipore) in a Luminex (Austin, TX, USA) 100 IS system as per the manufacturer's specifications. 
Plasma lipidic profile. Four weeks HFD fed mice plasma TAG (triacylglycerides), LDL (low-density lipoprotein-cholesterol), HDL (high-density lipoprotein-cholesterol), FCHO (free cholesterol), TCHO (total cholesterol), pancreatic lipase and NEFA (non-esterified fatty acids) were determined enzymatically using kinetic colorimetric kits (Spinreact, St Esteve de Bas, Girona, Spain) according to manufacturer's instructions.

Histological analysis and lesion quantification. Cryocut cross-sections $(5-\mu \mathrm{m})$ of aortic roots were evaluated for conventional hematoxylin-eosin and Oil Red O staining as previously described $(29,30)$. Images were captured with a Zeiss Axiophot microscope with a Plan-NEOFLUAR 10x/0.3 objective (Zeiss, Oberkochen, Germany) and a DP70 camera (Olympus, Southend-on-Sea, UK). Atherosclerotic lesion area in mice hearts and valves, expressed in percentage and mice splenic lipid content in the red pulps and white pulps were obtained as previously described $(29,30)$. Briefly, after mouse cardiac perfusion with PBS supplemented with $5 \mathrm{mM}$ of EDTA, mouse hearts were harvested and fixed in $4 \%$ paraformaldehyde for $24 \mathrm{~h}$ at $4^{\circ} \mathrm{C}$, passed through sucrose gradients at $10 \%$ and $20 \%$ (PBS supplemented with the respective concentration of sucrose), incubated $24 \mathrm{~h}$ in $30 \%$ sucrose, embedded in optimal cutting temperature, and cryopreserved at $-80^{\circ} \mathrm{C}$. Cryocut cross sections $(8 \mu \mathrm{m})$ were evaluated for conventional hematoxylin-eosin (HE) staining. Images were captured with a Zeiss Axiophot microscope with a Plan-Neofluar 310/0.3 objective (Carl Zeiss, Oberkochen, Germany) and a DP70 camera (Olympus, Tokyo, Japan). To avoid specific biases due to potential differences in lesion shape, cross sections of the entire lesion were analyzed and averaged. For splenic samples, same fixation and cryopreservation was performed. After being cut, tissues underwent Oil Red O (Sigma) staining to detect neutral lipids. Both the planimetric area of atherosclerotic plaques (hearts) and the lipids area (spleens) was measured in pixels using ImageJ (NIH) and quantified.

Immunostaining. Immunofluorescence assays were performed as described before $(29,30)$. In brief, mice spleens and hearts were fixed overnight for $24 \mathrm{~h}$ at $4^{\circ} \mathrm{C}$, passed through sucrose gradients at $10 \%$ and $20 \%$ (PBS supplemented with the respective concentration of sucrose), incubated $24 \mathrm{~h}$ in $30 \%$ sucrose, embedded in optimal cutting temperature, and cryopreserved at $-80^{\circ} \mathrm{C}$. Afterwards, they were sectioned into $5 \mu \mathrm{m}$ sections with a microtome (Jung RM2055; Leica Microsystems, Wetzlar, Germany). CryoSection samples slides were rehydrated, subjected to antigen retrieval in $10 \mathrm{mM}$ citrate buffer ( $\mathrm{pH} 6.0)$, blocked, and stained with antibodies specific for mouse Ly6G (1:100; Becton Dickinson), histone 3 citrullinated (1:200; Abcam), CXCL12 (1:100; Abcam), followed by secondary staining using standard procedures. Secondary antibodies for immunofluorescence were Alexa Fluor 647-conjugated anti-rabbit (Thermo Fisher), Alexa Fluor 594-conjugated anti-rat (Thermo Fisher), FITC-conjugated anti-rat (Sigma). Nuclei were counterstained with DAPI (Thermo Fisher). Immunofluorescence staining of cryo-sections were mounted in Prolong Gold Antifade mounting medium (Thermo Fisher). Primary control panel was performed with an appropriate isotype control $\mathrm{IgG}$, and secondary controls incubations were performed in the absence of primary antibody. For the TUNEL technology assays, same methodology was used added to TUNEL kit (In Situ Cell Death Detection Kit, Fluorescein; Roche) manufacturer's specifications. A LSM710 confocal microscope with a Plan-Apochromat 325/0.8 oil immersion objective (Carl Zeiss) was used to capture images from immunofluorescence staining. Images were analyzed using ImageJ [National Institutes of Health (NIH), Bethesda, MD, USA]. and were processed for presentation with Zen2009 (Carl Zeiss) software.

Western blot analysis. Mouse splenic samples were snap-frozen in liquid nitrogen and stored at $-80^{\circ} \mathrm{C}$. Subsequent processing was carried out according to previous protocols $(29,30)$. In summary, protein extracts from mouse tissues were obtained using ice-cold proprietary detergent in $25 \mathrm{mM}$ Bicine, $150 \mathrm{mM}$ $\mathrm{NaCl}$ ( $\mathrm{pH}$ 7.6) (T-PER: Tissue Protein Extraction Reagent; Thermo Fisher) supplemented with phosphatase cocktail and protease inhibitors (Sigma). Proteins were resolved on SDS-PAGE gels and then transferred to nitrocellulose membranes. Proteins were detected using rabbit pAb against NOD1 (1:500; Abcam), rabbit mAb against phospho-RIPK2 (1:1000; Cell Signaling, Danvers, MA, USA), rabbit pAb against phospho-RIPK2 (1:1000; Cell Signaling), rabbit pAb against LOX1 (1:1000; Abcam), rabbit mAb against phospho-p65 (1:1000; Cell Signaling), rabbit mAb against p65 (1:1000; Cell Signaling), rabbit pAb against histone 3 citrullinated (1:1000; Abcam), rabbit mAb against phospho-ERK (1:1000; Cell Signaling), rabbit mAb against ERK (1:1000; Cell Signaling), rabbit mAb against phospho-p38 (1:1000; Cell Signaling), rabbit mAb against p38 (1:1000; Cell Signaling), rabbit mAb against phospho-TAK1 (1:1000; Cell 
Signaling), rabbit mAb against TAK1 (1:1000; Cell Signaling), rabbit mAb against phospho-IKK $\alpha \beta$ 1:1000; Cell Signaling), rabbit mAb against IKK $\beta$ (1:1000; Cell Signaling), mouse mAb against $\alpha$-tubulin (1:4000; Sigma) and horseradish peroxidase-conjugated secondary antibodies (Bio-Rad, Hercules, CA, USA). Protein bands were visualized using a Luminata chemiluminescence detection system (Merck Millipore) and an Image-Quant LAS 500 imager (GE Healthcare Life Sciences, Freiburg, Germany) and were quantified using ImageJ. Intensities of each protein bands were expressed as a percentage of those of the tubulin.

qRT-PCR. Total RNA was isolated by homogenization in a TissueLyser LT with QUIAZOL and eluted using MinElute columns (Qiagen; Madrid, Spain). RNA integrity was assessed by RNA Nano Chip (Agilent Technologies; Madrid, Spain). $250 \mathrm{ng}$ of RNA were retro-transcribed by using High-Capacity cDNA Reverse Transcription Kit (Applied Biosystems; Madrid, Spain). SYBR Green assay was conducted in 7900HT Fast Real-Time PCR System equipment for qRT-PCR detection of the indicated genes (Supplemental Table S1). Calculations were obtained from measurement of technical triplicates of each sample. The relative amount of mRNA was calculated with the comparative $2^{-\Delta \Delta \mathrm{Ct}}$ method using mouse Hprt1 or human GAPDH, respectively, as endogenous control transcripts.

Quantification and statistical analysis. All the values are expressed as means \pm SD. GraphPad Prism 6 (GraphPad Software Inc.; San Diego, CA, USA) was employed to perform the statistical analysis. After calculating for normality by D'Agostino-Pearson omnibus test, a non-parametric test (Mann-Whitney Utest), or a parametric test (unpaired Student's t test with Welch's correction) was used as the most appropriate in each case. One-way ANOVA followed by Bonferroni's post hoc tests was used for multiple comparisons. Statistical significance was considered at $\mathrm{P}$ values $<0.05$. Removal of outliers was performed by ROUT method. Statistical tests and $\mathrm{P}$ values are indicated for each panel in the corresponding figure legends. The number of individual animals (n) for in vivo and ex vivo experiments is provided in each figure.

\section{Results}

Deletion of Nod1 enhances leukocyte blood accumulation under high fat and hypercholesterolemic diet (HFD), but activation of NOD1 favors increased levels of splenic myeloid cells. First, we determined the effect of genetic deletion of Nodl in mice fed chow or HFD for 4 weeks on the mobilization of immune cells from the bone marrow to the circulation and to the spleen (Figure 1A-C). While there are no significant changes in leukocyte population counts in these three tissues under chow diet, HFD establishes significant variations between mouse genotypes. These data support the importance of the simultaneous conditions of HFD and NOD1-deficiency to the alterations of the leukocyte populations observed in these three hematopoietic niches: Nod $^{-/}$HFD-fed mice showed a decrease in bone marrow $\mathrm{CD} 45^{+}$cells and an increase in both circulating and splenic levels of these cells, as it is also determined in specific subsets of $\mathrm{CD}_{4} 5^{+}$cells ( $\mathrm{Ly} 6 \mathrm{C}^{+}$, $\mathrm{Ly}_{6 \mathrm{G}}{ }^{+}$and splenic F4/80 ${ }^{+}$cells).

To better assess the role of splenic NOD1 on leukocyte mobilization under HFD, one of the best models is to study this molecule under an $A p o e^{-/-}$background $(29,30)$, a condition that favors atherogenesis. In this regard, Apoe ${ }^{-/} \mathrm{Nodl}^{-/}$mice fed chow diet did not show significant changes in the mobilization of cells from the bone marrow to the blood and spleen (Supplemental Figure S1). However, this situation was changed in Apoe $^{-/} \mathrm{Nodl}^{-/}$mice fed HFD for 4 weeks. As Figure 2A shows, serum levels of the chemoattractants CCL2, CXCL1 (neutrophils) and CXCL2 (monocytes and macrophages) were significantly increased, due to HFD and the fact that, in the absence of NOD1, the cell infiltration in the atheromatous plaque is reduced as previously described (29-31). Other chemokines like the chemoattractant CCL5 (mainly a chemotactic factor for T cell recruitment to inflammatory sites) did not exhibit significant changes. These changes agreed with a decrease in the bone marrow $\mathrm{CD} 45^{+}$population and an increase in circulating CD $45^{+}, \mathrm{CD} 11 \mathrm{~b}^{+} \mathrm{Ly}_{6 \mathrm{C}^{+}}$and $\mathrm{CD} 11 \mathrm{~b}^{+} \mathrm{Ly}_{6 \mathrm{G}}{ }^{+}$cells (Figure 2B). Interestingly, Apoe $^{-/}$mice fed HFD exhibit an increase in $\mathrm{CD} 45^{+}$and $\mathrm{CD} 11 \mathrm{~b}^{+} \mathrm{Ly} 6 \mathrm{G}^{+}$cells in the spleen when comparted to Apoe ${ }^{-/-} \mathrm{Nod1}^{-/-}$mice, which suggests that in the absence of NOD1 the infiltration of circulating immune cells is attenuated (Figure 2C). Moreover, pharmacological activation of NOD1, with the NOD1-agonist iE-DAP, enhances this recruitment of inflammatory cells in the spleen (Figure 2C). This situation has been previously described (30). 
In addition to these data, $A p o e^{-/-} N_{o d 1^{--}}$mice exhibited an increase in their circulating leukocytes, mainly due to higher levels of neutrophils and inflammatory monocytes (Supplemental Figure S2A). However, no statistically significant differences were observed between the main circulating cell populations in Apoe $^{-/}$vs. Apoe ${ }^{-/}$Nod1 $^{-/}$HFD fed mice after splenic artery-ligation (Supplemental Figure S2B). Moreover, as Supplemental Figure S3A shows, spleen ligation in Apoe $e^{-/}$mice resulted in enhanced bone marrow mRNA levels of Nodl and in the chemokine Cxcl12, which is involved in chemotaxis of lymphocytes and considered as a coronary artery risk factor $(3,32-34)$. In addition, Apoe ${ }^{-/}$NodI $^{-/}$sham operated animals exhibited specific changes in some genes committed in the function of the bone marrow and in the differentiation and fate of hematopoietic cells, such as Spil, Gcsfr, Kit and Cd47 (Supplemental Figure S3B-C). Of note that spleen ligation in $A p o e^{--} \mathrm{Nod}^{-/}$mice increased or involved additional specific genes in the bone marrow, such as Spil, Gatal, Csfrl, Dngrl and Irf8, but decreased the levels of others, such as Kit, Gcsfr and Cd47.

These data suggest that decreased splenic function alters the normal performance of the bone marrow in Apoe $^{--} \mathrm{Nodl}^{-/}$mice under HFD (Supplemental Figure S3B). However, Apoe ${ }^{-/} \mathrm{Nod}^{-/}$mice have minimal differences $v s$. Apoe $e^{-/}$counterparts in terms of expression of cell adhesion molecules in the spleen (Supplemental Figure S3C).

Splenic NOD1 modulates plasma lipid levels and atheroma plaque progression. Since the spleen is a key component in extramedullary hematopoiesis we evaluated the role of NOD1 under pro-atherogenic conditions $(1,4,16)$. As Suppl. Figure S4A-B shows, splenic Nodl mRNA levels remained unchanged in mice fed chow diet, but were increased in $A p o e^{--}$mice fed HFD. Nod2 mRNA levels did not present important changes under both chow or HFD. Moreover, NOD1 protein levels and activity were increased as deduced by the phosphorylation of the downstream target RIPK2. Furthermore, as previously described (35), absence of NOD1 in Apoe-deficient mice fed HFD resulted in increased body weight; however, this effect was attenuated after spleen artery-ligation, suggesting a role for the spleen in this enhanced body weight. These conditions (sham operated vs. spleen-artery ligation) did not alter the spleen mass in mice fed HFD (Suppl. Figure S4C).

To determine the level of activation of the NOD1 dependent-pathway in the spleen from mice fed HFD, splenic extracts were prepared from Apoe $e^{-/}, A_{p o e^{-/}} N_{o d l}{ }^{-/}$and Apoe ${ }^{-/-}$mice receiving intraperitoneally the NOD1 agonist iE-DAP (24h prior to sacrifice) after 4 weeks of HFD. As Supplemental Figure S4D shows, in addition to RIPK2 phosphorylation, P-TAK1, a downstream target from P-RIPK2 also exhibited a minimal although statistically significant increase, which suggests that maximal NOD1 activation is not achieved only by feeding HFD. As expected, Apoe $e^{-/} N o d 1^{-/}$mice failed to show this signaling. To evaluate the role of splenic NOD1 on atheroma dynamics, Apoe ${ }^{-/-}$and Apoe $e^{--} N_{\text {odI }}{ }^{-/-}$mice were submitted to sham operation or splenic artery-ligation and fed HFD for 4 weeks. As Figure 3A shows, deletion of NOD1 reduced the atheromatous lesion in sham operated mice, as previously described (2931). Interestingly, a significant reduction in the progression of the atheromatous lesion was also observed in Apo $^{-/-}$animals that underwent spleen artery-ligation, even lesser than that observed in sham operated

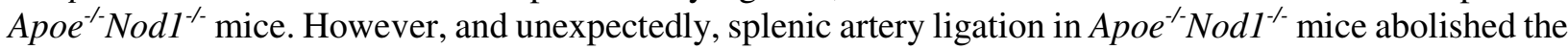
decreased atheromatous lesion observed in the absence of NOD1 (Figure 3A). These data indicate that the presence of the splenic remnant in the body provides signals that modulate atherogenesis, in addition to the modulatory effects dependent on NOD1 activation. Figure 3A (right panel) shows representative images of the lesion size.

This protective role of NOD1 after splenic artery-ligation was not associated to changes in the serum levels of triglycerides (TAG) or LDL; in fact, Apoe $e^{-/-}$od $^{-/-}$mice exhibited higher levels of LDL regardless spleen sham or artery ligation. Interestingly, ligation enhanced HDL and NEFA levels, which can be associated to the protective role of NOD1 under these conditions (Figure 3B). Additionally, other humoral and cellular factors associated to spleen ligation need to be consired.

\section{Absence of NOD1 improves splenic lipid homeostasis and enhances neutrophil mobilization from the}


bone marrow. Absence of Nod1 in HFD-fed Apoe--mice does not alter Nod2 levels in the spleen but increases the expression of genes involved in the efflux of cholesterol (i.e., Abcal and Abcgl) at the time that decreases the expression of the oxLDL receptor Lox 1 (Figure 4A). LOX1 protein levels also decreased in splenic Apoe ${ }^{-/} \mathrm{Nod}^{-/-}$mice (Figure 4B). Accordingly, the lipid content, especially in the red pulp of the spleen, decreased in Apoe ${ }^{-/} \mathrm{Nod}^{-/}$mice vs. Apoe ${ }^{-/}$counterparts (Figure 4C). Interestingly, the bone marrow from Apoe $e^{-/}$mice exhibited lesser content $v s$. Apoe ${ }^{-/} \mathrm{Nod}^{-/}$counterparts of cells expressing Ly6g, Mpo and Padi4, genes associated to neutrophil content and function $(29,30,36-41)$; however, this profile was completely reversed after spleen ligation, suggesting that splenic NOD1 has a significant role in bone marrow retention of neutrophils (Figure 4D). Interestingly, the levels of $C d 68$, encoding for a receptor associated to macrophage capture of LDL particles, was elevated in the absence of NOD1, regardless splenic function (sham or splenic artery-ligation).

Deletion of NOD1 alters splenic composition and reduces the release of neutrophil extracellular traps (NETs). One interesting feature of the spleen composition from Apo $e^{-/-} N o d 1^{-/}$mice fed HFD is the reduced presence of neutrophils as deduced by the decreased expression levels of the neutrophil markers $L y 6 g$ and Mpo (Figure 5A). This is despite the increase in serum levels of chemoattractants (Figure 2A) and chemokines involved in leukocyte recruitment, such as Cxcl12 (Figure 5A). Indeed, other alterations in gene transcription in the spleen related to splenic transendothelial migration (Figure 5B) or NETs formation (Figure 5A), were observed in Apoe ${ }^{-/}$NodI $^{-/}$mice after 4 weeks on HFD. In addition, we quantified the levels of Ly6G $\mathrm{G}^{+}$splenic cells (Figure 5C) that were significantly decreased in Apoe ${ }^{-/} \mathrm{Nod1}^{-1-}$ mice. Since neutrophils produce NETs, leading to NETosis, the amounts of H3Cit. (marker of NETs $(42,43)$ ) and the chemotactic CXCL12 were quantified in splenic sections from Apoe $e^{-/}$and Apoe $e^{-/}$Nod1 $^{-/}$mice. As Figure 5D shows, NETosis, determined by the H3Cit. content was decreased in sham operated Apoe $e^{-/-}$Nod1 $^{-/}$vs. Apoe $^{-/}$mice, whereas an increase in CXCL12 was observed in these sections, in agreement with the mRNA levels (Figure 5A). Similar results were observed after spleen ligation (Figure 5E).

Analysis of TUNEL ${ }^{+}$cells in the splenic $\mathrm{Ly} 6 \mathrm{G}^{+}$population showed higher percentages in the white pulp of Apoe $e^{-/}$vs. Apoe ${ }^{-/} \mathrm{Nod}^{-/}$mice regardless splenic function (sham or after artery ligation; Figure 6A). These differences were significantly enhanced in the red pulp of the spleens after artery ligation (Figure 6A). To assess the extent of NETs formation under these conditions, Apoe $e^{-/}$and Apoe $^{-\gamma}$ mice challenged with iE-DAP were compared to Apoe $e^{-/} N o d 1^{--}$mice. As Figure 6B shows, an increase in P-p65, P-ERK and P-p38, and mainly in H3Cit. content was evidenced in Apoe $e^{-/-}$and Apoe ${ }^{-/}$treated with iE-DAP. These results suggest that, in the absence of NOD1, the citrullination of histone H3, as marker of NETs formation was significantly undetected in the spleen. Also, the enhanced response observed after iE-DAP treatment suggests that NOD1 from splenic Apoe $e^{-/}$mice retained capacity to fully express the maximal activity of this NOD1-dependent NETosis.

\section{Discussion}

The role of the spleen in the aftermath of several diseases remains a conflictive issue due to its complexity in cell composition and cell-to-cell interactions $(11,34,44)$, the presence of highly specialized microcompartments, and to the continuous blood flow through this tissue $(11,45,46)$. In fact, most of the physiopathological performances of the spleen have been deduced after traumatic or therapeutic total or partial surgical removal of the organ. This is important since, in USA for example, more than 20,000 surgical splenectomies per year are performed and the side effects of these interventions are poorly studied (47). Indeed, partial splenectomy remains a surgical option versus complete spleen removal in order to preserve organ function and to avoid severe consequences resulting from the impairment of its normal metabolism (20,48-51).

Here, we have investigated the role of the splenic NOD-like receptor NOD1 in both leukocyte trafficking and in the subsequent progress of atherogenesis in mice fed HFD, as previously observed (29-31) . First, we observed that splenic NOD1 was increased and was active in the spleen of Apoe ${ }^{-/}$mice fed HFD, as reflected by the presence of downstream targets, such as phospho-RIPK2, phospho-TAK1 or phospho-p65 
from the NF- $\kappa B$ pathway. This was probably due to the presence of oxidized LDL particles coming from the HFD/hypercholesterolemic diet and to molecules derived from the microbiota (peptidoglycans) that are agonists of NOD1 $(29,30,35,52,53)$. This activation of the NOD1 pathway was near the range of the activity achieved after administration of the NOD1 agonist iE-DAP. Interestingly NOD2 mRNA levels remained unchanged under these conditions. Moreover, even in the absence of NOD1, NOD2 levels did not change, pointing to a specific key role for NOD1 in the response of the spleen to HFD. However, this role of NOD1 seems to be paradoxical in terms of leukocytes mobilization from the bone marrow. Our data show that Apoe ${ }^{-/} \mathrm{Nod}^{-/-}$, compared to Apoe ${ }^{-/-}$mice, exhibit an enhanced presence of chemoattractant chemokines in the serum of animals fed HFD, in particular CCL2, CXCL1 (54) and CXCL2 (55,56). Under this context, a flow of $\mathrm{CD} 45^{+}$cells from the bone marrow to systemic circulation, but not to the spleen, occurs. Among them, immature myeloid cells $\left(\mathrm{Ly} 6 \mathrm{C}^{+} \mathrm{CD} 11 \mathrm{~b}^{+}\right)$appear to exit the bone marrow and have been previously characterized $(57,58)$. We hypothesized that part of these cells are mobilized towards the spleen due to the enhanced presence of CXCL12 in this organ (34). In addition, this seems to be a direct effect of the HFD since the same type of mobilizations were observed in $A p o e^{-/}$mice. These data fit with previous work using an alternative model of mice atherogenesis $\left(L d l r^{--}\right)$fed HFD (54). These mice also exhibit enhanced levels of circulating chemoattractants and accumulation of neutrophils in the spleen with citrullinated histone H3. Furthermore, diets rich in saturated fatty acids enhance the depletion of cells from the bone marrow, whereas diets rich in polyunsaturated fatty acids contribute to retention of neutrophils in the bone marrow, in line with our data (59).

HFD-fed Apoe $^{-/}$mice are a classical model for induction of atherogenesis (60). Here we show that the fine-tuning of atherogenesis progression was also modulated by the spleen itself since splenic arteryligation leads to a significant reduction in the atherogenic lesion extent. One possibility to explain these results is the increase of NETs and TUNEL ${ }^{+} / \mathrm{Ly} 6 \mathrm{G}^{+}$cells in $A p o e^{-/-}$mice after spleen ligation. However, whereas we confirmed that $A p o e^{--} N_{o d 1}{ }^{-1}$ mice exhibit a reduced atheromatous lesion due to a reduced recruitment of circulating inflammatory cells $(30,31)$, splenic artery-ligation failed to support this protection, reflecting the involvement of different mechanisms in atherogenesis progression. Moreover, analysis of the lipidic profile in these animals showed minimal, but statistically significant, differences between $\mathrm{Apoe}^{-/}$and Apoe $e^{-/} \mathrm{Nod1}^{-/}$mice in LDL levels and increased HDL levels after splenic arteryligation. Overall, Apoe ${ }^{-/} \mathrm{Nod}^{-/}$mice showed a decreased lipid content in the spleen, which implies that splenic NOD1 activation was involved in lipid regulation and accumulation in this organ. In this regard, the contribution of the spleen to atherosclerotic disease has been stressed by various groups $(4,5,16,61,62)$. A summary of the role of the spleen in the context of Nodl and Apoe deficiency and the signaling involved in atherogenic progression is shown in Supplemental Figure S5.

Finally, our results support the view that both the spleen and the activation of NOD1 in splenic cells have a significant impact on the progress of atherogenesis under HFD. Furthermore, these results open the way for the design of novel therapeutic strategies based on NOD1 inhibition under conditions of plaque progression and potential atherothrombotic events.

\section{Concluding remarks}

The involvement of the NLRs, and in particular of NOD1, in many inflammatory diseases is a growing field that links and stress the importance of the diet and the metabolic changes derived from it in both the host microbiota and the immune system. This is because NOD1 agonists from the gut microbiota can access systemic circulation, playing a relevant function in gastrointestinal immune-metabolic adaptations. Here, we describe the role of splenic NOD1 activation in the outcome of the diet-induced atherogenesis and mobilization of different leukocyte populations from the bone marrow to vascular lesions. In addition to this, our data show that NOD1 activation in splenic murine neutrophils is able to signal and promote the formation of NETs that actively participate in the enhancement of the innate immune response. The exact role of these NETs formation is unclear but it can help to provide additional clues to understand the mechanisms that contribute to the regulation of innate immunity and the potential adverse effects in the progression of low-grade pro-inflammatory diseases. 


\section{Statements and Declarations}

Ethics approval and consent to participate: Animal study approval. The institutional ethics committee approved animal studies. All animal procedures conformed to EU Directive 2010/63 and Recommendation 2007/526/EC regarding the protection of animals used for experimental and other scientific purposes, enforced in Spanish law (RD 53/2013).

Consent for publication: All authors concur and approve the submission of the manuscript.

Availability of data and material: The data generated and analyzed during the current study are available upon request to the authors.

Competing interests: The authors have no relevant financial or non-financial interests to disclose

Acknowledgements: The authors thank the services of microscopy and genomics from the Institute of Biomedical Research Alberto Sols, for technical support.

Author contributions: V.F.-G. designed the study, performed experiments, analyzed data, wrote the paper, designed the figures and revised the manuscript. S.G.-R. designed and performed experiments, analyzed data and provided intellectual input and improvements P.M.-S., C.D and A. C. provided intellectual input. D-G.-C provided intellectual input and revised the manuscript. J.A.-O. participated in neutrophil experiments and provided intellectual input L.B. wrote the paper, provided funding and intellectual input and discussed and organized the information. All authors read and approved the final manuscript.

Funding sources: This work has been supported by: Ministerio de Ciencia, Investigación y Universidades, Agencia Estatal de Investigación 10.13039/501100011033 (PID2019-104284RB-I00, PID2020113238RB-I00, RTI2018-098113B-I00, PID2019-108977RB-I00), Centro de Investigación Biomédica en Red en Enfermedades Cardiovasculares (CB16/11/00222) and Consorcio de Investigación en Red de la Comunidad de Madrid, S2017/BMD-3686, Fondo Social Europeo and Fondo Europeo de Desarrollo Regional.

\section{References}

1. Orphanidou-Vlachou E, Tziakouri-Shiakalli C, Georgiades CS. Extramedullary hemopoiesis. Semin Ultrasound CT MR (2014) 35:255-262. doi:S0887-2171(13)00146-7 [pii] 10.1053/j.sult.2013.12.001

2. Wu C, Ning H, Liu M, Lin J, Luo S, Zhu W, Xu J, Wu W-C, Liang J, Shao C-K, et al. Spleen mediates a distinct hematopoietic progenitor response supporting tumor-promoting myelopoiesis. J Clin Invest (2018) 128:3425-3438. doi:10.1172/JCI97973

3. Inra CN, Zhou BO, Acar M, Murphy MM, Richardson J, Zhao Z, Morrison SJ. A perisinusoidal niche for extramedullary haematopoiesis in the spleen. Nature (2015) 527:466-471. doi:10.1038/nature15530

4. Fernández-García V, González-Ramos S, Martín-Sanz P, Castrillo A, Boscá L. Contribution of Extramedullary Hematopoiesis to Atherosclerosis. The Spleen as a Neglected Hub of Inflammatory Cells. Front Immunol (2020) 11:586527. doi:10.3389/fimmu.2020.586527

5. Yang X, Chen D, Long H, Zhu B. The mechanisms of pathological extramedullary hematopoiesis in diseases. Cell Mol Life Sci (2020) 77:2723-2738. doi:10.1007/s00018-020-03450-w

6. Hu D, Al-Shalan HAM, Shi Z, Wang P, Wu Y, Nicholls PK, Greene WK, Ma B. Distribution of nerve fibers and nerve-immune cell association in mouse spleen revealed by immunofluorescent staining. Sci Rep (2020) 10:9850. doi:10.1038/s41598-020-66619-0

7. A-Gonzalez N, Castrillo A. Origin and specialization of splenic macrophages. Cell Immunol (2018) 330:151-158. doi:10.1016/j.cellimm.2018.05.005

8. Witztum JL. Splenic immunity and atherosclerosis: a glimpse into a novel paradigm? J Clin Invest (2002) 109:721-724. doi:10.1172/JCI15310 
9. Fayad ZA, Swirski FK, Calcagno C, Robbins CS, Mulder W, Kovacic JC. Monocyte and Macrophage Dynamics in the Cardiovascular System. J Am Coll Cardiol (2018) 72:2198-2212. doi:10.1016/j.jacc.2018.08.2150

10. Bazioti V, La Rose AM, Westerterp M. Myeloid cells regulate plasma LDL-cholesterol levels. Curr Opin Lipidol (2018) 29:233-239. doi:10.1097/MOL.0000000000000511

11. Cesta MF. Normal structure, function, and histology of the spleen. Toxicol Pathol (2006) 34:455465. doi:XR0G546G0G16372U [pii] 10.1080/01926230600867743

12. Fritz JH. Nod-like Receptors Have a Grip on Stem Cells. Cell Host Microbe (2014) 15:659-661. doi:10.1016/j.chom.2014.05.017

13. Burberry A, Zeng MY, Ding L, Wicks I, Inohara N, Morrison SJ, Núñez G. Infection Mobilizes Hematopoietic Stem Cells through Cooperative NOD-like Receptor and Toll-like Receptor Signaling. Cell Host Microbe (2014) 15:779-791. doi:10.1016/j.chom.2014.05.004

14. Nigro G, Rossi R, Commere P-H, Jay P, Sansonetti PJ. The Cytosolic Bacterial Peptidoglycan Sensor Nod2 Affords Stem Cell Protection and Links Microbes to Gut Epithelial Regeneration. Cell Host Microbe (2014) 15:792-798. doi:10.1016/j.chom.2014.05.003

15. Fatouros M, Bourantas K, Bairaktari E, Elisaf M, Tsolas O, Cassioumis D. Role of the spleen in lipid metabolism. Br J Surg (1995) 82:1675-1677. doi:10.1002/bjs.1800821230

16. Soehnlein O, Swirski FK. Hypercholesterolemia links hematopoiesis with atherosclerosis. Trends Endocrinol Metab (2013) 24:129-136. doi:S1043-2760(12)00187-7

17. Potteaux S, Ait-Oufella H, Mallat Z. Role of splenic monocytes in atherosclerosis. Curr Opin Lipidol (2015) 26:457-63. doi:10.1097/MOL.0000000000000223

18. Grasset EK, Duhlin A, Agardh HE, Ovchinnikova O, Hägglöf T, Forsell MN, Paulsson-Berne G, Hansson GK, Ketelhuth DFJ, Karlsson MCI. Sterile inflammation in the spleen during atherosclerosis provides oxidation-specific epitopes that induce a protective B-cell response. Proc Natl Acad Sci U S A (2015) 112:E2030-8. doi:10.1073/pnas.1421227112

19. Rezende AB, Neto NN, Fernandes LR, Ribeiro ACC, Alvarez-Leite JI, Teixeira HC. Splenectomy increases atherosclerotic lesions in apolipoprotein E deficient mice. J Surg Res (2011) 171:e231-6. doi:10.1016/j.jss.2011.08.010

20. Ai XM, Ho LC, Han LL, Lu JJ, Yue X, Yang NY. The role of splenectomy in lipid metabolism and atherosclerosis (AS). Lipids Heal Dis (2018) 17:186. doi:10.1186/s12944-018-0841-2 10.1186/s12944-018-0841-2 [pii]

21. Caligiuri G, Nicoletti A, Poirier B, Hansson GK. Protective immunity against atherosclerosis carried by B cells of hypercholesterolemic mice. J Clin Invest (2002) 109:745-753. doi:10.1172/JCI7272

22. Eichner ER. Splenic function: normal, too much and too little. J Exp Med (1979) 66:311-320. doi:10.1016/0002-9343(79)90554-0

23. Akan AA, Sengül N, Simşek S, Demirer S. The effects of splenectomy and splenic autotransplantation on plasma lipid levels. J Investig Surg Off J Acad Surg Res (2008) 21:369372. doi:10.1080/08941930802438898

24. Asai K, Kuzuya M, Naito M, Funaki C, Kuzuya F. Effects of splenectomy on serum lipids and experimental atherosclerosis. Angiology (1988) 39:497-504. doi:10.1177/000331978803900602

25. Chauhan A, Al Mamun A, Spiegel G, Harris N, Zhu L, McCullough LD. Splenectomy protects aged mice from injury after experimental stroke. Neurobiol Aging (2018) 61:102-111. doi:S01974580(17)30318-4 [pii] 10.1016/j.neurobiolaging.2017.09.022

26. Leone G, Pizzigallo E. Bacterial Infections Following Splenectomy for Malignant and Nonmalignant Hematologic Diseases. Mediterr J Hematol Infect Dis (2015) 7:e2015057. 
doi:10.4084/MJHID.2015.057

27. Lv Y, Lau WY, Li Y, Deng J, Han X, Gong X, Liu N, Wu H. Hypersplenism: History and current status. Exp Ther Med (2016) 12:2377-2382. doi:10.3892/etm.2016.3683

28. Kapoor P, Singh E, Radhakrishnan P, Mehta P. Splenectomy in plasma cell dyscrasias: a review of the clinical practice. Am J Hematol (2006) 81:946-954. doi:10.1002/ajh.20736

29. González-Ramos S, Fernández-García V, Recalde M, Rodríguez C, Martínez-González J, Andrés V, Martín-Sanz P, Boscá L. Deletion or Inhibition of NOD1 Favors Plaque Stability and Attenuates Atherothrombosis in Advanced Atherogenesis. Cells (2020) 9:2067. doi:10.3390/cells9092067

30. Gonzalez-Ramos S, Paz-Garcia M, Rius C, Del Monte-Monge A, Rodriguez C, Fernandez-Garcia V, Andres V, Martinez-Gonzalez J, Lasuncion MA, Martin-Sanz P, et al. Endothelial NOD1 directs myeloid cell recruitment in atherosclerosis through VCAM-1. Faseb J (2019) 33:39123921. doi:10.1096/fj.201801231RR

31. Kanno S, Nishio H, Tanaka T, Motomura Y, Murata K, Ihara K, Onimaru M, Yamasaki S, Kono $\mathrm{H}$, Sueishi K, et al. Activation of an innate immune receptor, Nod1, accelerates atherogenesis in Apoe-/- mice. J Immunol (2015) 194:773-780. doi:10.4049/jimmunol.1302841

32. Agarwal P, Li H, Paterson AJ, He J, Nagasawa T, Bhatia R. Role of CXCL12-Expressing Bone Marrow Populations in Leukemic Stem Cell Regulation. Blood (2016) 128:26-26. doi:10.1182/blood.V128.22.26.26

33. Christopher MJ, Liu F, Hilton MJ, Long F, Link DC. Suppression of CXCL12 production by bone marrow osteoblasts is a common and critical pathway for cytokine-induced mobilization. Blood (2009) 114:1331-1339. doi:10.1182/blood-2008-10-184754

34. Crane GM, Jeffery E, Morrison SJ. Adult haematopoietic stem cell niches. Nat Rev Immunol (2017) 17:573-590. doi:10.1038/nri.2017.53

35. González-Ramos S, Paz-García M, Fernández-García V, Portune KJ, Acosta-Medina EF, Sanz Y, Castrillo A, Martín-Sanz P, Obregon MJ, Boscá L. NOD1 deficiency promotes an imbalance of thyroid hormones and microbiota homeostasis in mice fed high fat diet. Sci Rep (2020) 10:12317. doi:10.1038/s41598-020-69295-2

36. Trilleaud C, Gauttier V, Biteau K, Girault I, Belarif L, Mary C, Pengam S, Teppaz G, Thepenier $\mathrm{V}$, Danger R, et al. Agonist anti-ChemR23 mAb reduces tissue neutrophil accumulation and triggers chronic inflammation resolution. Sci Adv (2021) 7:eabd1453. doi:10.1126/sciadv.abd1453

37. Tall AR, Yvan-Charvet L, Westerterp M, Murphy AJ. Cholesterol efflux: a novel regulator of myelopoiesis and atherogenesis. Arterioscler Thromb Vasc Biol (2012) 32:2547-2552. doi:10.1161/ATVBAHA.112.300134

38. Servant G, Weiner OD, Herzmark P, Balla T, Sedat JW, Bourne HR. Polarization of chemoattractant receptor signaling during neutrophil chemotaxis. Science (2000) 287:1037-1040.

39. Ekman AK, Cardell LO. The expression and function of Nod-like receptors in neutrophils. Immunology (2010) 130:55-63. doi:IMM3212 [pii] 10.1111/j.1365-2567.2009.03212.x

40. Clarke TB, Davis KM, Lysenko ES, Zhou AY, Yu Y, Weiser JN. Recognition of peptidoglycan from the microbiota by Nod1 enhances systemic innate immunity. Nat Med (2010) 16:228-231. doi:nm.2087 [pii] 10.1038/nm.2087

41. Westerterp M, Gourion-Arsiquaud S, Murphy AJ, Shih A, Cremers S, Levine RL, Tall AR, YvanCharvet L. Regulation of hematopoietic stem and progenitor cell mobilization by cholesterol efflux pathways. Cell Stem Cell (2012) 11:195-206. doi:S1934-5909(12)00335-9 [pii] 10.1016/j.stem.2012.04.024

42. Tsourouktsoglou T-D, Warnatsch A, Ioannou M, Hoving D, Wang Q, Papayannopoulos V. Histones, DNA, and Citrullination Promote Neutrophil Extracellular Trap Inflammation by 
Regulating the Localization and Activation of TLR4. Cell Rep (2020) 31:107602. doi:10.1016/j.celrep.2020.107602

43. Deng Q, Pan B, Alam HB, Liang Y, Wu Z, Liu B, Mor-Vaknin N, Duan X, Williams AM, Tian Y, et al. Citrullinated Histone H3 as a Therapeutic Target for Endotoxic Shock in Mice. Front Immunol (2020) 10:2957. doi:10.3389/fimmu.2019.02957

44. den Haan JM, Mebius RE, Kraal G. Stromal cells of the mouse spleen. Front Immunol (2012) 3:e201. doi:10.3389/fimmu.2012.00201

45. Dutta P, Hoyer FF, Grigoryeva LS, Sager HB, Leuschner F, Courties G, Borodovsky A, Novobrantseva T, Ruda VM, Fitzgerald K, et al. Macrophages retain hematopoietic stem cells in the spleen via VCAM-1. J Exp Med (2015) 212:497-512. doi:10.1084/jem.20141642

46. Steiniger B, Bette M, Schwarzbach H. The Open Microcirculation in Human Spleens. J Histochem Cytochem (2011) 59:639-648. doi:10.1369/0022155411408315

47. Wechter D. Spleen removal. Online. Last update: 2020, March. [Cited 2020, April]. Available from: URL: https://medlineplus.gov/ency/article/002944.htm. Medlin NIH (2020)

48. Costi R, Castro Ruiz C, Romboli A, Wind P, Violi V, Zarzavadjian Le Bian A. Partial splenectomy: Who, when and how. A systematic review of the 2130 published cases. J Pediatr Surg (2019) 54:1527-1538. doi:10.1016/j.jpedsurg.2018.11.010

49. Robinette CD, Fraumeni Jr. JF. Splenectomy and subsequent mortality in veterans of the 1939-45 war. Lancet (1977) 2:127-129. doi:S0140-6736(77)90132-5 [pii] 10.1016/s0140-6736(77)90132-5

50. Luu S, Spelman D, Woolley IJ. Post-splenectomy sepsis: preventative strategies, challenges, and solutions. Infect Drug Resist (2019) 12:2839-2851. doi:10.2147/IDR.S179902

51. Sun LM, Chen HJ, Jeng LB, Li TC, Wu SC, Kao CH. Splenectomy and increased subsequent cancer risk: a nationwide population-based cohort study. Am J Surg (2015) 210:243-251. doi:S0002-9610(15)00173-7 [pii] 10.1016/j.amjsurg.2015.01.017

52. Bird L. A NOD to neutrophils. Nat Rev Immunol (2010) 10:157-157. doi:10.1038/nri2739

53. Philpott DJ, Sorbara MT, Robertson SJ, Croitoru K, Girardin SE. NOD proteins: regulators of inflammation in health and disease. Nat Rev Immunol (2014) 14:9-23. doi:10.1038/nri3565

54. Osaka M, Deushi M, Aoyama J, Funakoshi T, Ishigami A, Yoshida M. High-Fat Diet Enhances Neutrophil Adhesion in LDLR-Null Mice Via Hypercitrullination of Histone H3. JACC Basic to Transl Sci (2021) 6:507-523. doi:10.1016/j.jacbts.2021.04.002

55. De Filippo K, Dudeck A, Hasenberg M, Nye E, van Rooijen N, Hartmann K, Gunzer M, Roers A, Hogg N. Mast cell and macrophage chemokines CXCL1/CXCL2 control the early stage of neutrophil recruitment during tissue inflammation. Blood (2013) 121:4930-4937. doi:10.1182/blood-2013-02-486217

56. Deshmane SL, Kremlev S, Amini S, Sawaya BE. Monocyte Chemoattractant Protein-1 (MCP-1): An Overview. J Interf Cytokine Res (2009) 29:313-326. doi:10.1089/jir.2008.0027

57. Meng L, Almeida LN, Clauder A-K, Lindemann T, Luther J, Link C, Hofmann K, Kulkarni U, Wong DM, David J-P, et al. Bone Marrow Plasma Cells Modulate Local Myeloid-Lineage Differentiation via IL-10. Front Immunol (2019) 10:1183. doi:10.3389/fimmu.2019.01183

58. Bronte V, Brandau S, Chen S-H, Colombo MP, Frey AB, Greten TF, Mandruzzato S, Murray PJ, Ochoa A, Ostrand-Rosenberg S, et al. Recommendations for myeloid-derived suppressor cell nomenclature and characterization standards. Nat Commun (2016) 7:12150. doi:10.1038/ncomms12150

59. Svahn SL, Gutiérrez S, Ulleryd MA, Nookaew I, Osla V, Beckman F, Nilsson S, Karlsson A, Jansson J-O, Johansson ME. Dietary Polyunsaturated Fatty Acids Promote Neutrophil Accumulation in the Spleen by Altering Chemotaxis and Delaying Cell Death. Infect Immun 
(2019) 87:e00270-19. doi:10.1128/IAI.00270-19

60. Getz GS, Reardon CA. Animal models of atherosclerosis. Arter Thromb Vasc Biol (2012)

32:1104-1115. doi:10.1161/ATVBAHA.111.237693

61. Swirski FK, Nahrendorf M, Etzrodt M, Wildgruber M, Cortez-Retamozo V, Panizzi P, Figueiredo J-L, Kohler RH, Chudnovskiy A, Waterman P, et al. Identification of splenic reservoir monocytes and their deployment to inflammatory sites. Science (2009) 325:612-616. doi:10.1126/science.1175202

62. Li Y, Stone JR. The impact of splenectomy on human coronary artery atherosclerosis and vascular macrophage distribution. Cardiovasc Pathol Off J Soc Cardiovasc Pathol (2016) 25:453-460. doi:10.1016/j.carpath.2016.08.001 


\section{Legends to figures}

Figure 1. Absence of NOD1 alters bone marrow and circulating immune cells profile in mice fed highfat diet (HFD) for four weeks. Wild type (WT) and $\mathrm{Nod}^{-/}$male mice were fed chow or HFD for four weeks and the amount and distribution of $\mathrm{CD}^{4} 5^{+}$cells were determined in the bone marrow (A), blood (B) and in the spleen $(\mathrm{C})$. The content of $\mathrm{CD} 45^{+}$cells and the $\mathrm{CD} 11 \mathrm{~b}^{+} \mathrm{Ly} 6 \mathrm{C}^{+}, \mathrm{CD} 11 \mathrm{~b}^{+} \mathrm{Ly} 6 \mathrm{G}^{+}$populations were determined. The $\mathrm{CD} 115^{+} \mathrm{F} 4 / 80^{+}$population was quantified in the bone marrow and spleen. Results show the mean \pm SD from 8 animals of each condition. Statistical significance was estimated as $\mathrm{P}$ value calculated by un-paired $t$ test; $* \mathrm{P}<0.05 ; * * \mathrm{P}<0.01 ; * * * \mathrm{P}<0.005 v s$. the same nutritional condition in WT mice.

Figure 2. Absence of NOD1 under an Apoe $^{-/}$background enhances the mobilization of $\mathrm{CD}^{+} 5^{+}$cells from the bone marrow to the blood and their accumulation, while NOD1 activation favors leukocyte ontogeny in the bone marrow and splenic infiltration in mice fed high-fat diet (HFD) for four weeks. (A) Circulating of selected chemokines levels in Apoe $e^{-/}$and Apoe $e^{-/} N o d 1^{-/}$mice after four weeks of HFD. (B) Quantification of bone marrow (BM) and circulating immune cells from mice described in panel A. (C) Analysis of the distribution of $\mathrm{CD} 45^{+}$cells and $\mathrm{CD} 11 \mathrm{~b}^{+} \mathrm{Ly}_{6 \mathrm{G}}{ }^{+}$in the spleen of these mice. To ensure maximal activation of NOD1, Apoe ${ }^{--}$mice were challenged intraperitoneally with the NOD1 agonist iEDAP $\left(1 \mathrm{mg} / \mathrm{kg}\right.$ body weight) $24 \mathrm{~h}$ prior to sacrifice, and the CD45 ${ }^{+}$and $\mathrm{CD} 11 \mathrm{~b}^{+} \mathrm{Ly} 6 \mathrm{G}^{+}$cells were quantified. Results show the mean \pm SD from 9 animals of each condition $\left(\right.$ Apoe $^{-/}$and Apoe $e^{-/}$Nod1 $\left.^{--}\right)$. Statistical significance was estimated as $\mathrm{P}$ value calculated by un-paired $t$ test (panels $\mathrm{A}, \mathrm{B}$ ) or by one-way ANOVA followed by Bonferronis's post hoc multicomparisons analysis (panel C); $* \mathrm{P}<0.05 ; * * \mathrm{P}<0.01 ; * * * \mathrm{P}<0.005$ vs. the corresponding Apoe $e^{-/}$condition; ${ }^{\# \#} \mathrm{P}<0.005$ vs. the corresponding Apoe $e^{--} \mathrm{Nodl}^{-/}$.

Figure 3. Splenic artery-ligation reduces atherogenesis progression in Apoe $^{-/-}$mice fed HFD for four weeks. Apoe ${ }^{-/}$and Apoe $^{-/}$Nod1 $^{-/-}$mice were submitted to sham or splenic artery-ligation prior to start a 4 weeks HFD. The extent of the atherogenic lesion was determined by histochemistry. (A) Quantification of the atherogenic lesion in Apoe $e^{--}$and $A p o e^{-/-} N_{o d l^{--}}$mice after different spleen interventions and representative images of the atherogenic lesion in the heart from mice (B) Since splenic artery-ligation in Apoe $^{-/}$mice delayed the atherogenic progression, blood lipids and pancreatic lipase activity were measured in serum from these animals fed HFD for four weeks. Values were expressed as percentage $v s$. the sham Apoe $^{-/}$condition. Results show the mean \pm SD from 8 animals of each condition (sham and splenic arteryligation of $A p o e^{-/-}$and Apoe ${ }^{-/} \mathrm{Nod1}^{-/}$mice). Statistical significance was estimated as $\mathrm{P}$ value calculated by un-paired t test (panel A) or by one-way ANOVA followed by Bonferronis's post hoc multicomparisons analysis (panel $\mathrm{B}$ ); $* \mathrm{P}<0.05 ; * * \mathrm{P}<0.01 ; * * * \mathrm{P}<0.005 v s$. the corresponding splenic intervention condition $\left(\right.$ Apoe $^{-/}$or Apoe $^{--}$NodI $\left.^{-/}\right)$; ${ }^{\#} \mathrm{P}<0.05 ;{ }^{\# \#} \mathrm{P}<0.01 v$ s. the corresponding sham condition. Bar size is $100 \mu \mathrm{m}$ (panel A).

Figure 4. Apoe $^{-/-}$NodI $^{-/-}$mice fed HFD have reduced lipid content in the spleen and diminished neutrophil-associated biomarkers in the bone marrow. (A) Splenic mRNA levels of Nodl and Nod 2 genes and the cholesterol and lipid efflux genes Abcal and Abcgl, and the oxLDL receptor Loxl in Apoe ${ }^{-}$and Apoe $^{-/}$Nod1 $^{-/}$mice after 4 weeks of HFD. (B) Western blot analysis of the oxLDL receptor (LOX1) in samples from panel A. (C) Splenic lipid content in $A p o e^{-/}$and Apoe $e^{-/} N o d 1^{-/}$mice fed HFD. (D) mRNA levels of genes associated to neutrophil content in the bone marrow from sham and spleen-ligated mice. Results show the mean \pm SD from 7 animals of each condition (sham and ligation of Apoe ${ }^{-/}$and Apoe $^{-/}$ $\mathrm{Nodl}^{-}$mice). Statistical significance was estimated as $\mathrm{P}$ value calculated by un-paired $t$ test; * $\mathrm{P}<0.05$; $* * \mathrm{P}<0.01 ; * * * \mathrm{P}<0.005 v s$. the corresponding Apoe $^{-/}$condition. Bar size (panel C) is $100 \mu \mathrm{m}$.

Figure 5. Deletion of NOD1 reduces neutrophil content and NETs release in the spleen from mice fed HFD. (A-B) Splenic mRNA levels of genes related to neutrophil content in Apoe ${ }^{-/-}$and Apoe ${ }^{-/} N_{o d 1^{-/}}$mice fed HFD for 4 weeks. (C) Immunofluorescence analysis of $\mathrm{Ly}^{+} \mathrm{G}^{+}$cells and DAPI staining in splenic sections from Apoe ${ }^{-/}$and Apoe $^{-/} \mathrm{Nod}^{-/-}$mice after 4 weeks of HFD. (D-E) Quantification of citrullinated 
histone $\mathrm{H} 3$ associated to $\mathrm{Ly}_{6 \mathrm{G}}{ }^{+}$cells $\left(\mathrm{H} 3 \mathrm{Cit}^{+}{ }^{+} \mathrm{Ly}_{6 \mathrm{G}}{ }^{+}\right.$) and $\mathrm{CXCL} 12$ in spleen sections from Apoe ${ }^{-/}$and Apoe $^{-/} \mathrm{Nod1}^{-/}$mice (sham or after spleen artery-ligation) fed 4 weeks HFD. Results show the mean \pm SD from 8 animals of each condition (sham and artery ligation of $A p o e^{-/-}$and $\mathrm{Apoe}^{-{ }_{-}} \mathrm{Nodl}^{-/}$mice). Statistical significance was estimated as $\mathrm{P}$ value calculated by un-paired $t$ test; $* \mathrm{P}<0.05 ; * * \mathrm{P}<0.01 ; * * * \mathrm{P}<0.005$ vs. the corresponding Apoe $e^{-/-}$condition. Bar size (panels D-E) is $50 \mu \mathrm{m}$.

Figure 6. Spleen ligation reduces apoptosis and neutrophil splenic content in NOD1 deficient mice fed HFD. Quantification of (A) TUNEL ${ }^{+} \mathrm{Ly}_{6 \mathrm{G}^{+}}$cells in the splenic red pulp and white pulp from sham and spleen artery-ligated Apoe $e^{--}$and Apoe $e^{-/} \mathrm{Nodl}^{-/}$mice fed HFD for 4 weeks. (B) Western blot analysis of proteins related to NETs and NETosis from Apoe $e^{-/}$, Apoe $e^{-/} \mathrm{Nodl}^{-/}$and Apoe ${ }^{-/}$mice challenged intraperitoneally with iE-DAP ( $1 \mathrm{mg} / \mathrm{kg}$ body weight) $24 \mathrm{~h}$ prior to sacrifice. Results show the mean $\pm \mathrm{SD}$ from 7 animals of each condition (sham and ligation of Apoe $e^{-/}$and Apoe ${ }^{-/}$Nod1 $^{-/}$mice). Statistical significance was estimated as $\mathrm{P}$ value calculated by un-paired $t$ test (panel A) o by one-way ANOVA followed by Bonferronis's post hoc multicomparisons analysis (Panel A, ligation vs. sham; B); *P<0.05; ${ }^{* *} \mathrm{P}<0.01 ; * * * \mathrm{P}<0.005$ vs. the corresponding Apoe ${ }^{-/}$condition. ${ }^{\# \#} \mathrm{P}<0.01 ;{ }^{\# \#} \mathrm{P}<0.005$ vs. Apoe ${ }^{-/}$Nod1 $^{-/}$. 


\section{Figures}

A $\square$ WT $\square$ Nod1-
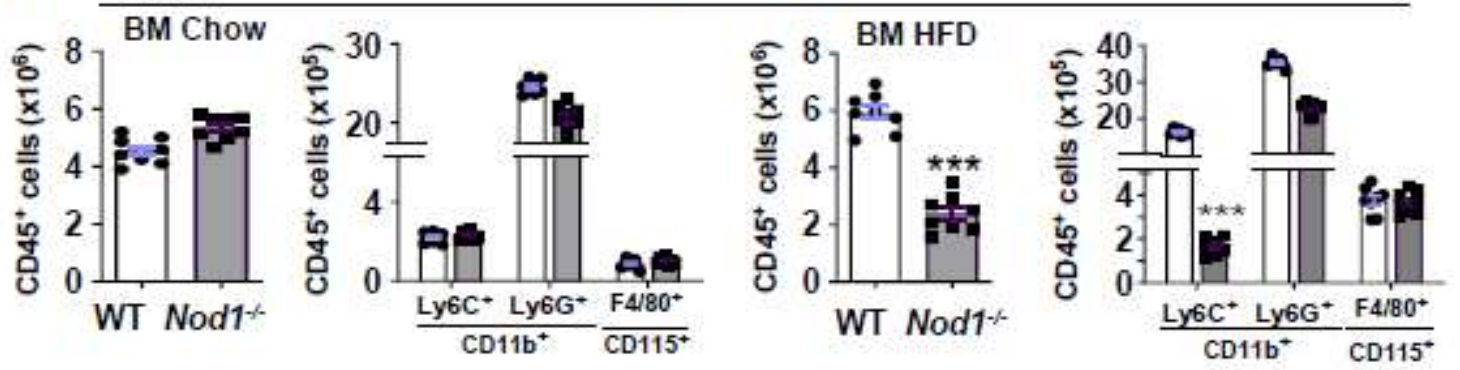

B
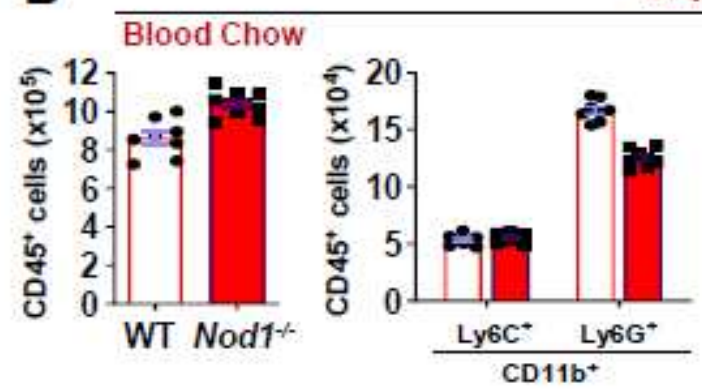

ㅁ WT $=$ Nod1+
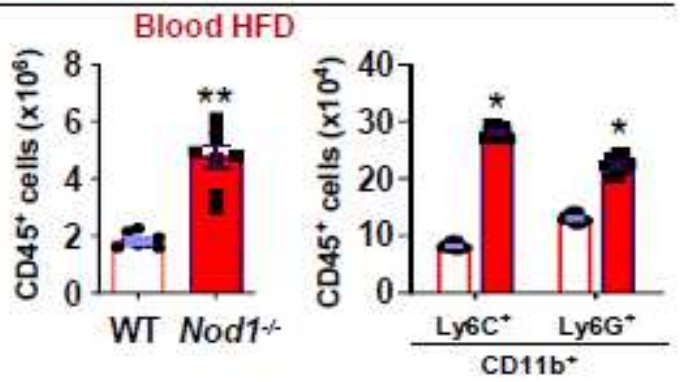

C

$\square$ WT $\square$ Nod1-
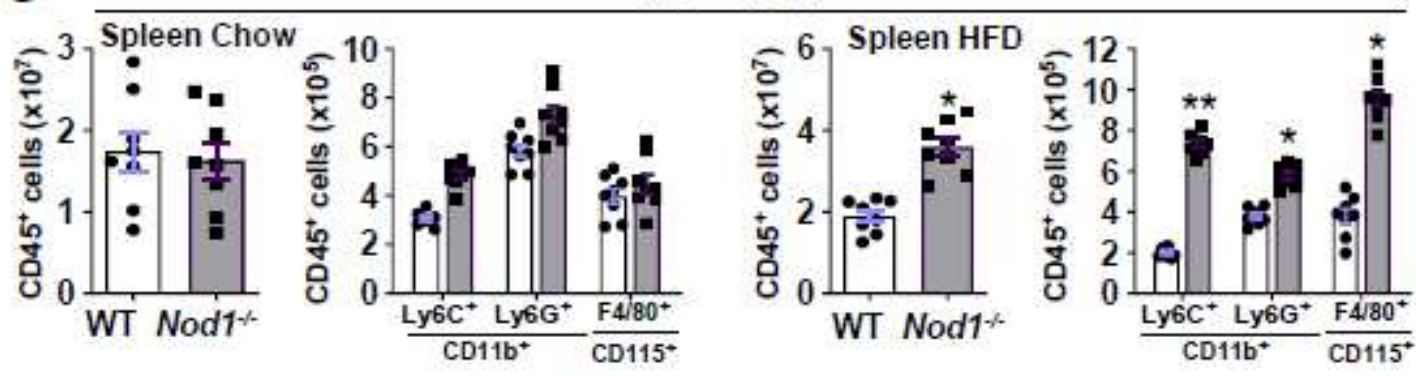

\section{Figure 1}

Absence of NOD1 alters bone marrow and circulating immune cells profile in mice fed high-fat diet (HFD) for four weeks. Wild type (WT) and Nod1-/- male mice were fed chow or HFD for four weeks and the amount and distribution of CD45+ cells were determined in the bone marrow (A), blood (B) and in the spleen $(C)$. The content of CD45+ cells and the CD11b+Ly6C+,CD11b+Ly6G+ populations were determined. The $\mathrm{CD} 115+\mathrm{F} 4 / 80+$ population was quantified in the bone marrow and spleen. Results show the mean + SD from 8 animals of each condition. Statistical significance was estimated as $P$ value calculated by un-paired $t$ test; ${ }^{*} P<0.05 ;{ }^{* \star P}<0.01 ; \star \star \star * P<0.005$ vs. the same nutritional condition in WT mice. 

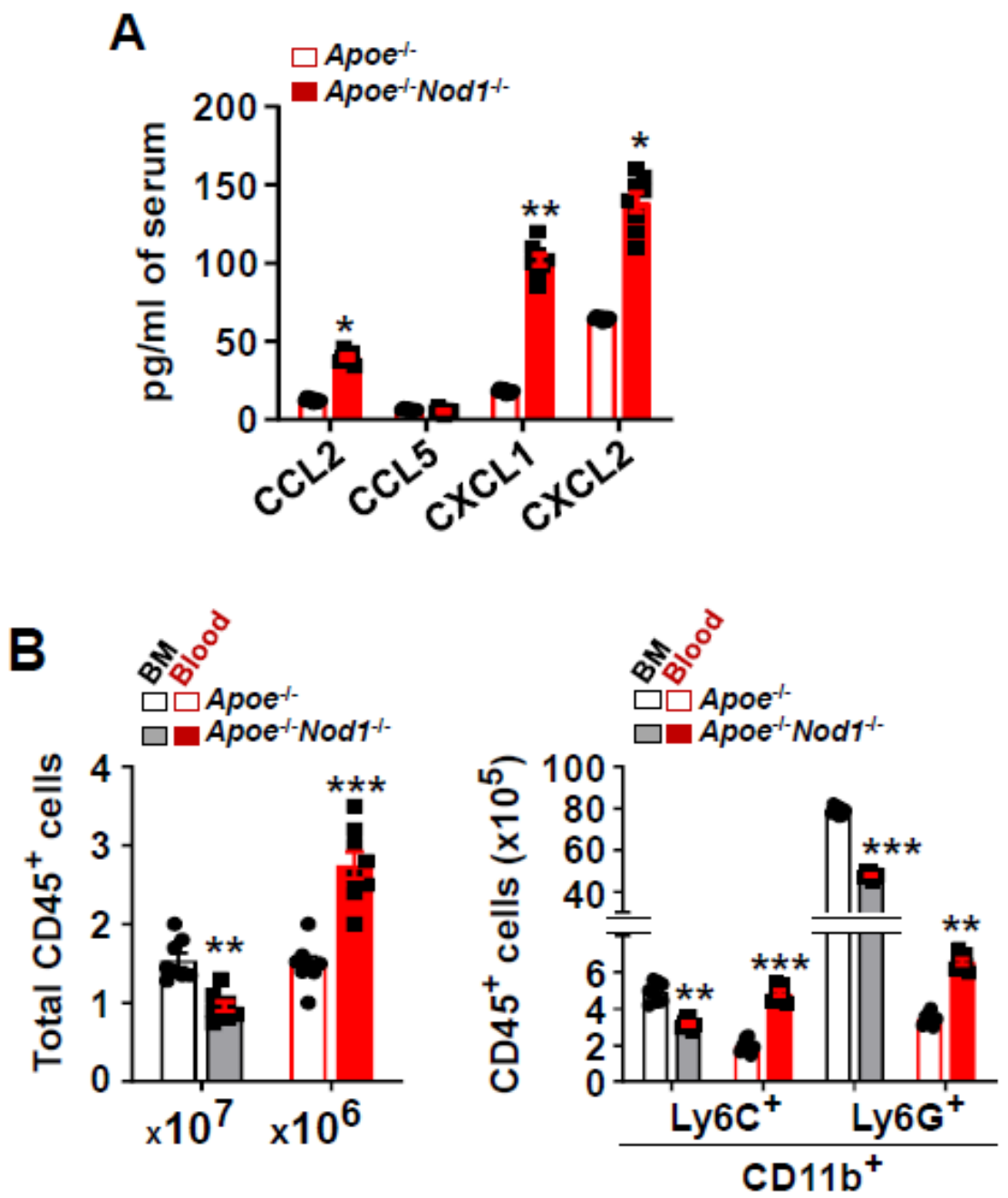

C
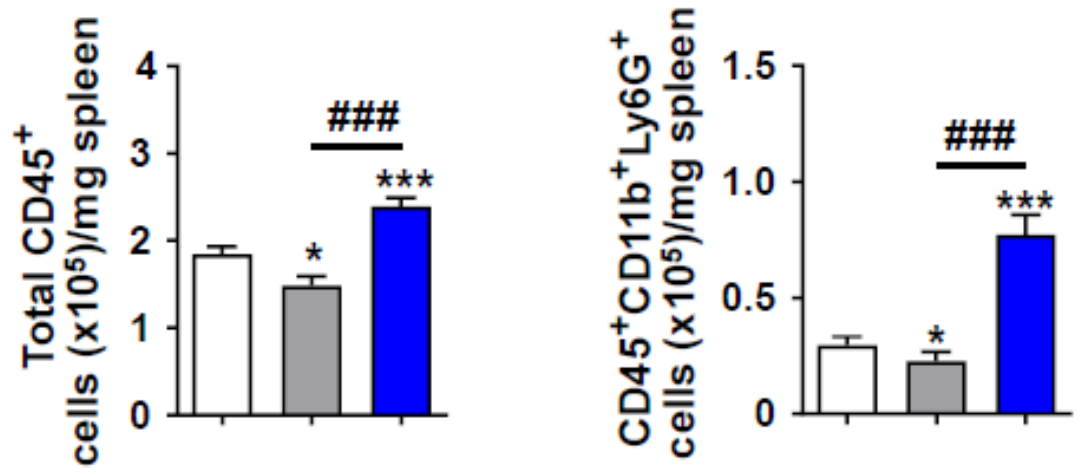

Figure 2

Absence of NOD1 under an Apoe-/- background enhances the mobilization of CD45+ cells from the bone marrow to the blood and their accumulation, while NOD1 activation favors leukocyte ontogeny in the bone marrow and splenic infiltration in mice fed high-fat diet (HFD) for four weeks. (A) Circulating of selected chemokines levels in Apoe-/- and Apoe-/-Nod1-/- mice after four weeks of HFD. (B) Quantification of bone marrow (BM) and circulating immune cells from mice described in panel A. (C) 
Analysis of the distribution of CD45+ cells and CD11b+Ly6G+ in the spleen of these mice. To ensure maximal activation of NOD1, Apoe-/- mice were challenged intraperitoneally with the NOD1 agonist iEDAP (1 mg/kg body weight) $24 \mathrm{~h}$ prior to sacrifice, and the CD45+ and CD11b+Ly6G+ cells were quantified. Results show the mean + SD from 9 animals of each condition (Apoe-/- and Apoe-/-Nod1-/-). Statistical significance was estimated as $P$ value calculated by un-paired $t$ test (panels $A, B$ ) or by oneway ANOVA followed by Bonferronis's post hoc multicomparisons analysis (panel $C$ ); ${ }^{*} P<0.05 ; * \star P<0.01$; $\star \star * P<0.005$ vs. the corresponding Apoe-/- condition; \#\#\#P<0.005 vs. the corresponding Apoe-/-Nod1-/-.
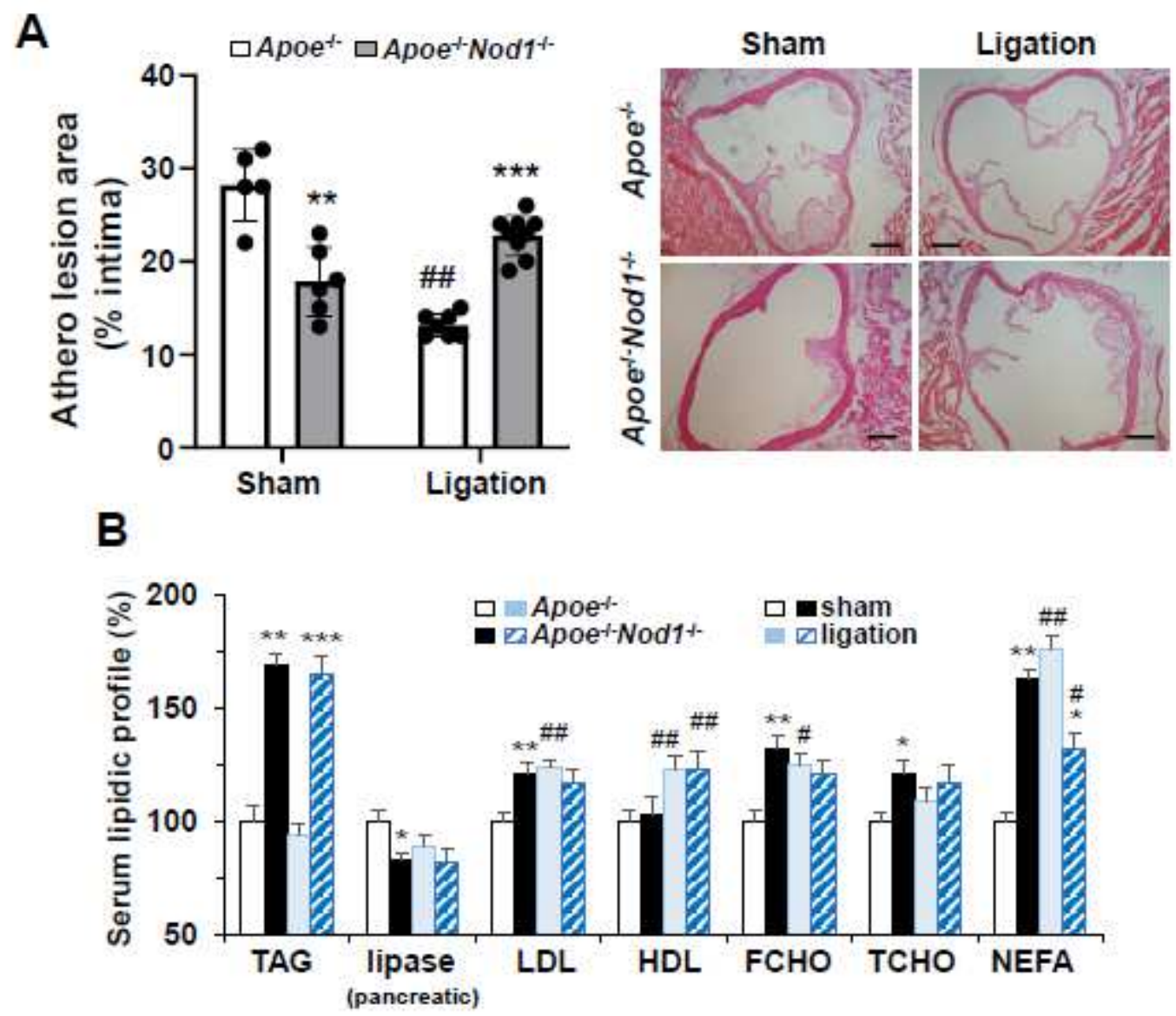

\section{Figure 3}

Splenic artery-ligation reduces atherogenesis progression in Apoe-/- mice fed HFD for four weeks. Apoe-/and Apoe-/-Nod1-/- mice were submitted to sham or splenic artery-ligation prior to start a 4 weeks HFD. The extent of the atherogenic lesion was determined by histochemistry. (A) Quantification of the atherogenic lesion in Apoe-/- and Apoe-/-Nod1-/- mice after different spleen interventions and representative images of the atherogenic lesion in the heart from mice (B) Since splenic artery-ligation in Apoe-/- mice delayed the atherogenic progression, blood lipids and pancreatic lipase activity were measured in serum from these animals fed HFD for four weeks. Values were expressed as percentage vs. the sham Apoe-/- condition. Results show the mean + SD from 8 animals of each condition (sham and splenic artery-ligation of Apoe-/- and Apoe-/-Nod1-/- mice). Statistical significance was estimated as P value calculated by un-paired $t$ test (panel $A$ ) or by one-way ANOVA followed by Bonferronis's post hoc 
multicomparisons analysis (panel $B$ ); ${ }^{*}<<0.05 ;{ }^{*} P<0.01 ; * \star * P<0.005$ vs. the corresponding splenic intervention condition (Apoe-/- or Apoe-/-Nod1-/-); \#P<0.05; \#\#P<0.01 vs. the corresponding sham condition. Bar size is $100 \mu \mathrm{m}$ (panel $\mathrm{A})$.

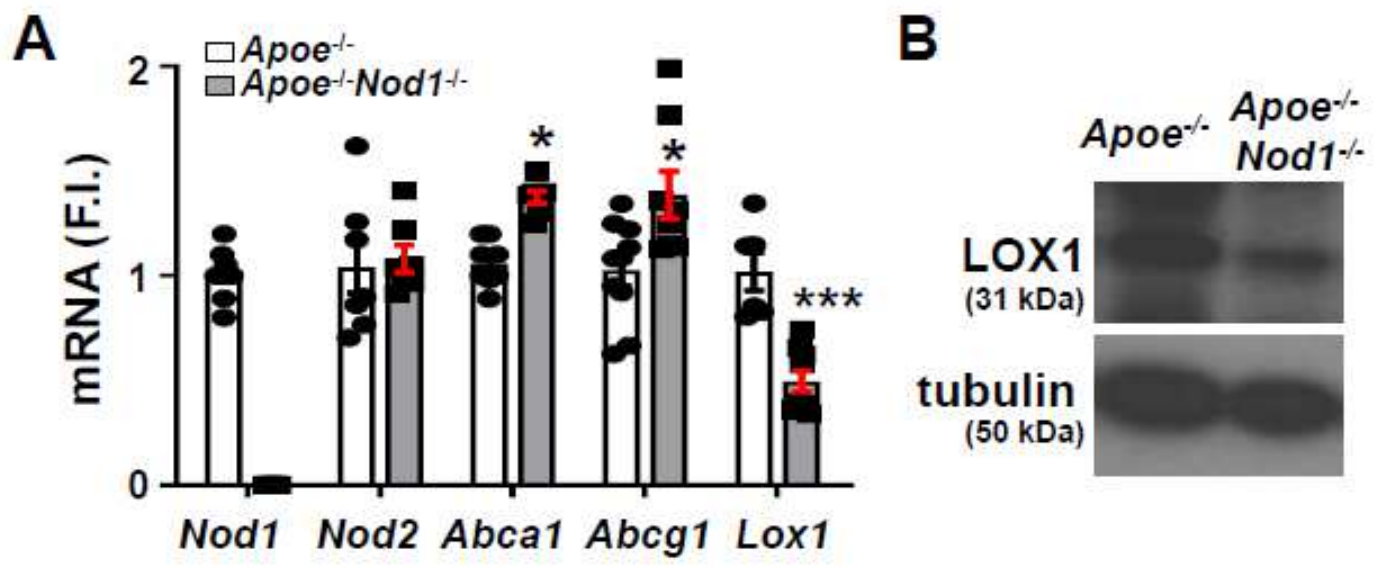

C
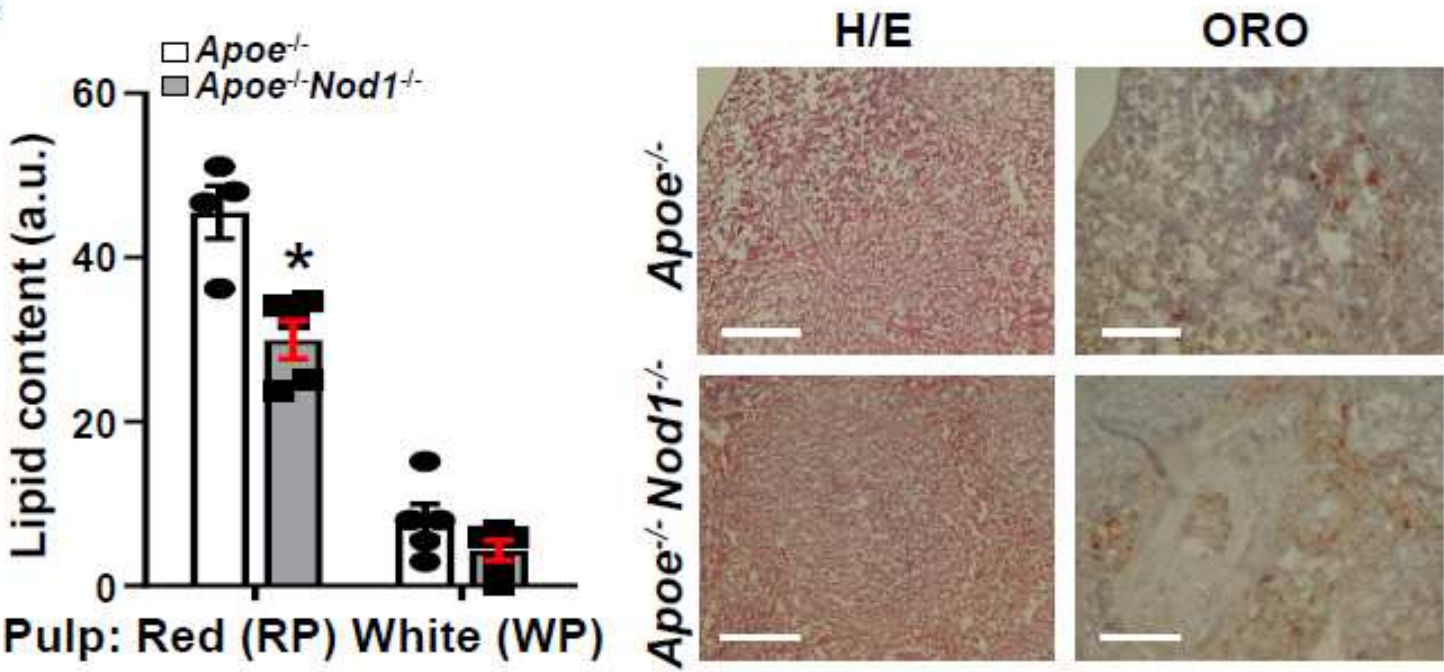

D
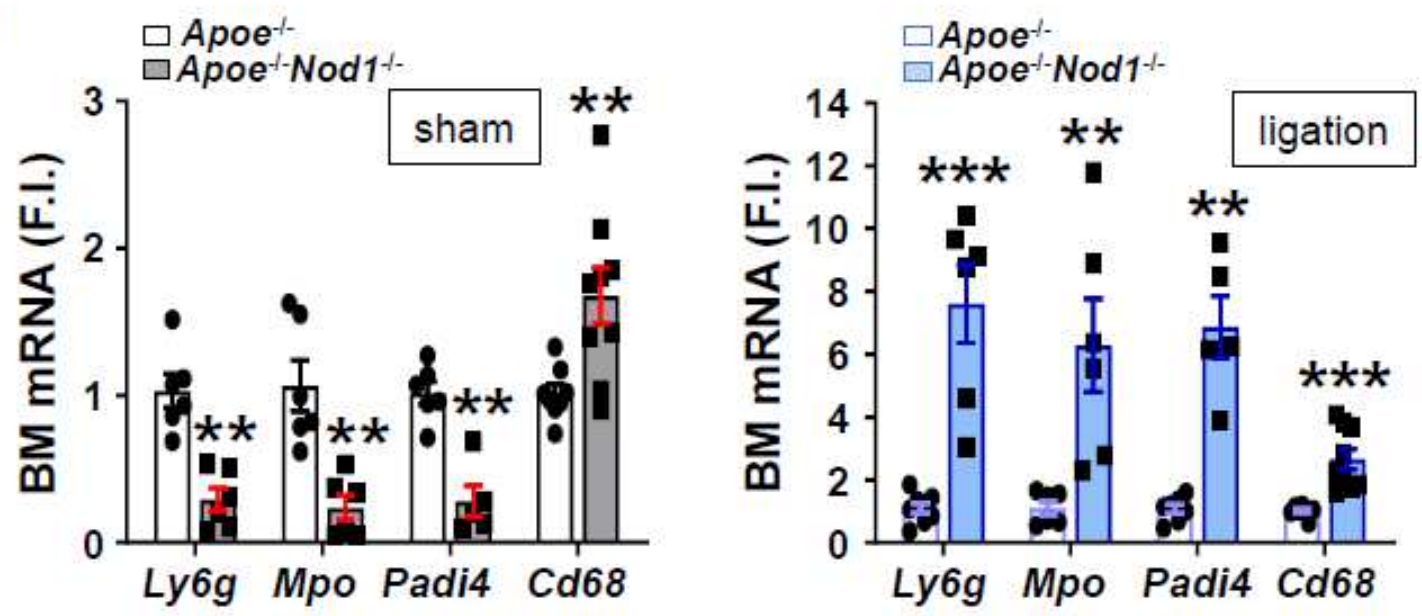

Figure 4 
Apoe-/-Nod1-/- mice fed HFD have reduced lipid content in the spleen and diminished neutrophilassociated biomarkers in the bone marrow. (A) Splenic mRNA levels of Nod1 and Nod2 genes and the cholesterol and lipid efflux genes Abca1 and Abcg1, and the oxLDL receptor Lox1 in Apoe-/- and Apoe-/Nod1-/- mice after 4 weeks of HFD. (B) Western blot analysis of the oxLDL receptor (LOX1) in samples from panel A. (C) Splenic lipid content in Apoe-/- and Apoe-/-Nod1-/- mice fed HFD. (D) mRNA levels of genes associated to neutrophil content in the bone marrow from sham and spleen-ligated mice. Results show the mean + SD from 7 animals of each condition (sham and ligation of Apoe-/- and Apoe-/-Nod1-/mice). Statistical significance was estimated as $P$ value calculated by un-paired $t$ test; ${ }^{*} P<0.05 ; \star \star P<0.01$; $\star \star \star P<0.005$ vs. the corresponding Apoe- $/$ - condition. Bar size (panel C) is $100 \mu \mathrm{m}$. 
A

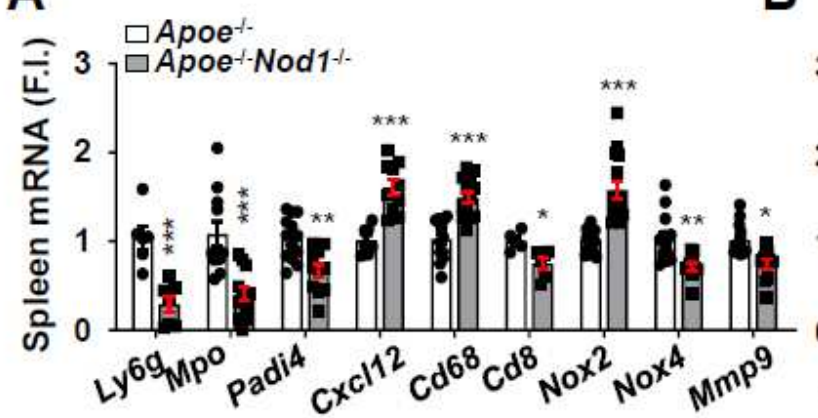

B

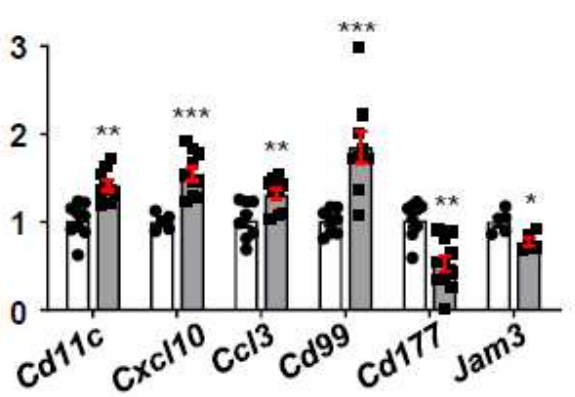

C

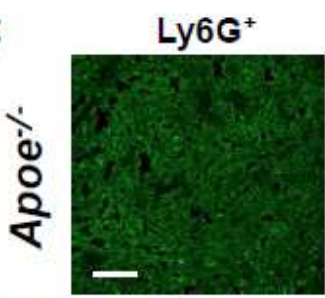

DAPI

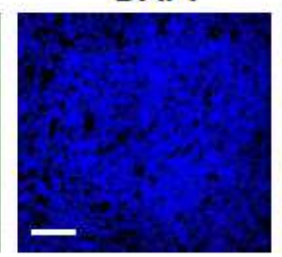

merge

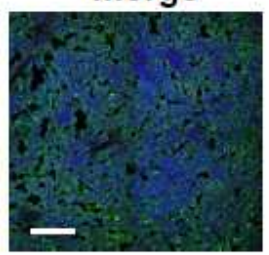

WP (a.u.): 100

$\operatorname{RP}$ (a.u.): $\quad 100$

Total Ly6G+(a.u.): 100

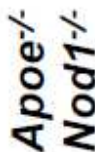

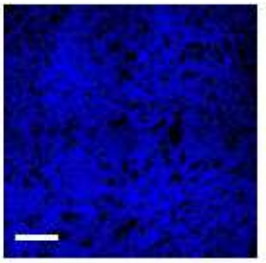

D

H3Cit. ${ }^{+}$Ly6G $^{+}$

(a.u.)

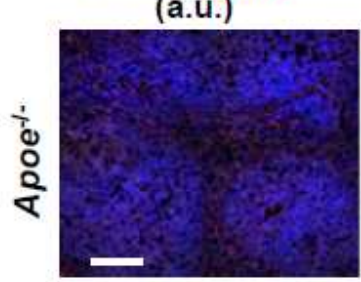

WP: $\quad 2.1 \pm 0.2$

RP: $19.5 \pm 1.5$

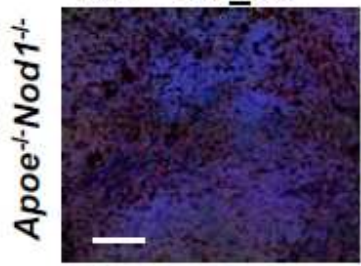

WP: $0.35 \pm 0.10^{\star \star *}$ WP: $36.2 \pm 0.1^{\star \star \star}$

RP: $\quad 5.5 \pm 0.8^{* \star *}$ RP: $18.4 \pm 0.8^{\star * *}$
E

$\square \square$ Apoe ${ }^{-/} \square=$ Apoe $^{-l}$ Nod ${ }^{-/}$
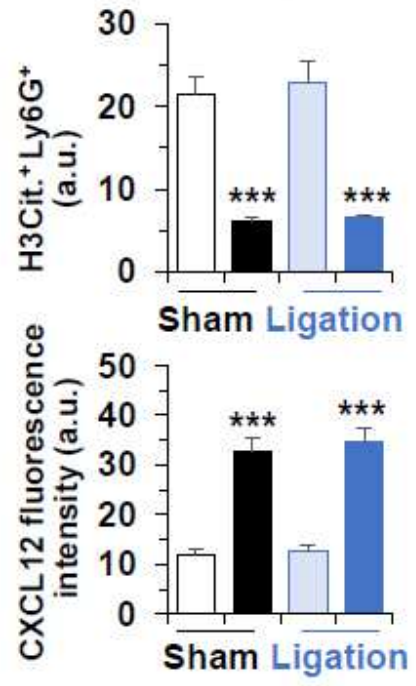

Figure 5

Deletion of NOD1 reduces neutrophil content and NETs release in the spleen from mice fed HFD. (A-B) Splenic mRNA levels of genes related to neutrophil content in Apoe-/- and Apoe-/-Nod1-/- mice fed HFD for 4 weeks. (C) Immunofluorescence analysis of Ly6G+ cells and DAPI staining in splenic sections from Apoe-/- and Apoe-/-Nod1-/- mice after 4 weeks of HFD. (D-E) Quantification of citrullinated histone H3 associated to Ly6G+ cells (H3Cit.+ Ly6G+) and CXCL12 in spleen sections from Apoe-/- and Apoe-/- 
Nod1-/- mice (sham or after spleen artery-ligation) fed 4 weeks HFD. Results show the mean + SD from 8 animals of each condition (sham and artery ligation of Apoe-/- and Apoe-/-Nod1-/- mice). Statistical significance was estimated as $P$ value calculated by un-paired $t$ test; ${ }^{*} P<0.05 ;{ }^{* \star P} P<0.01 ; * \star * P<0.005$ vs. the corresponding Apoe-/- condition. Bar size (panels D-E) is $50 \mu \mathrm{m}$.
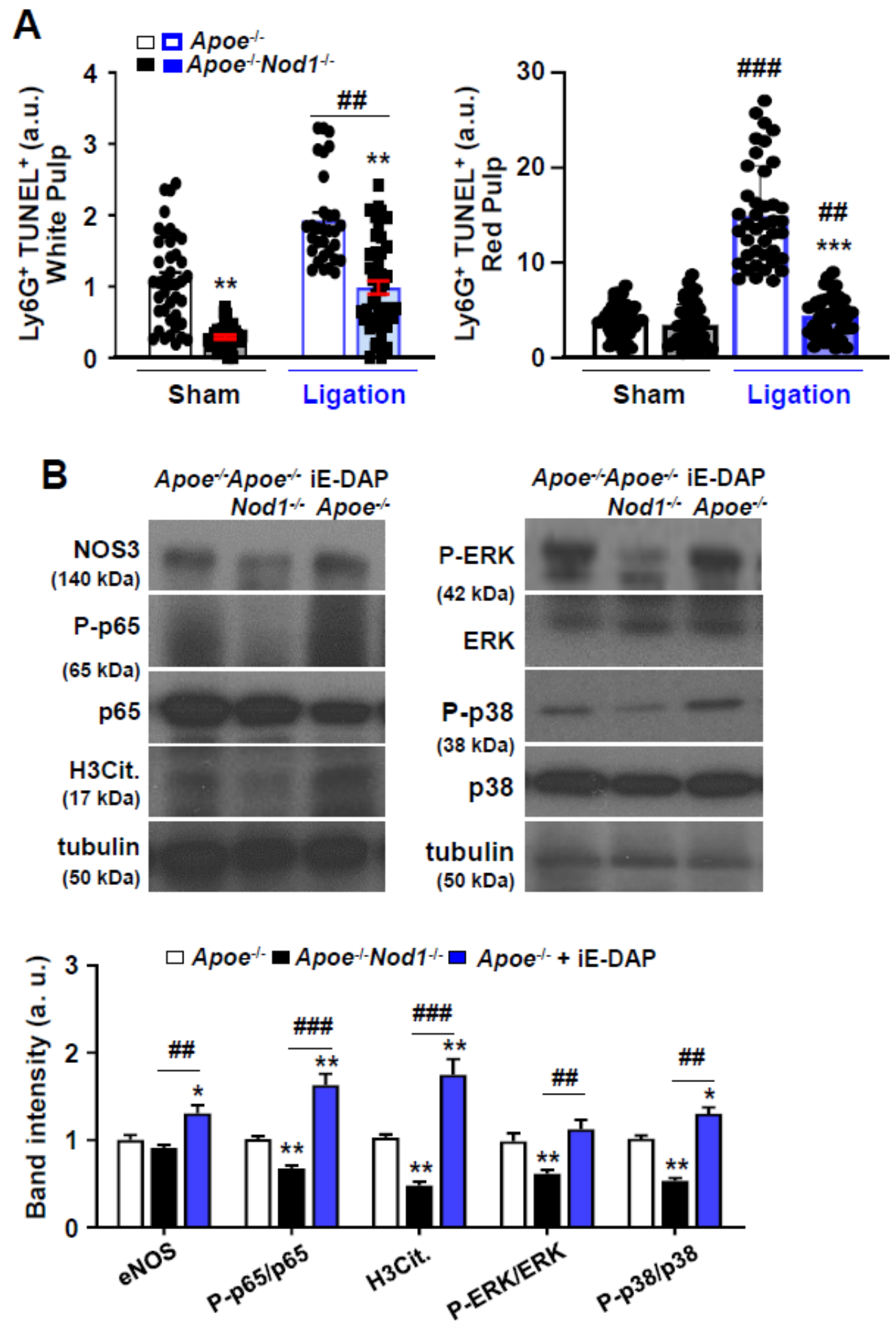

Figure 6 
Spleen ligation reduces apoptosis and neutrophil splenic content in NOD1 deficient mice fed HFD. Quantification of (A) TUNEL+ Ly6G + cells in the splenic red pulp and white pulp from sham and spleen artery-ligated Apoe-/- and Apoe-/-Nod1-/- mice fed HFD for 4 weeks. (B) Western blot analysis of proteins related to NETs and NETosis from Apoe-/-, Apoe-/-Nod1-/- and Apoe-/- mice challenged intraperitoneally with iE-DAP (1 mg/kg body weight) $24 \mathrm{~h}$ prior to sacrifice. Results show the mean + SD from 7 animals of each condition (sham and ligation of Apoe-/- and Apoe-/-Nod1-/- mice). Statistical significance was estimated as $P$ value calculated by un-paired $t$ test (panel $A$ ) o by one-way ANOVA followed by Bonferronis's post hoc multicomparisons analysis ( anel $A$, ligation vs. sham; $B$ ); ${ }^{*}<0.05 ;{ }^{* \star P}<0.01$;

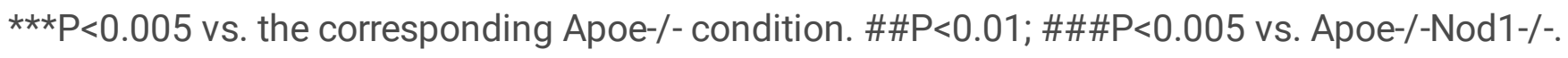

\section{Supplementary Files}

This is a list of supplementary files associated with this preprint. Click to download.

- SupplMat.pdf 